\title{
Complutum
}

ISSN: 1131-6993

\section{Un proyecto innovador en arqueología. El uso de material audiovisual como recurso didáctico en la enseñanza universitaria ${ }^{1}$}

\author{
Daniel Casado Rigalt ${ }^{2}$
}

Recibido: 07 de septiembre de 2018 / Aceptado: 30 de noviembre de 2018

Resumen. Los mecanismos de aprendizaje necesitan ser replanteados. El aula física se ha convertido en un espacio limitado de generación del conocimiento y la universidad ha caído en una trampa burocrática que lastra la viabilidad académica. La vídeo-lección y la vídeo-entrevista se están revelando como dos herramientas de enorme potencial, que complementan las clases presenciales y dinamizan la transferencia de contenidos. Permiten economizar recursos a largo plazo y rentabilizar el tiempo invertido por profesores y alumnos, dejando atrás el sistema de la toma de apuntes en las aulas. En el presente artículo se exponen las infinitas posibilidades del vídeo en la educación superior, así como la distinta acogida que está teniendo entre el estamento universitario. A modo de muestreo ha sido sondeada la aceptación del vídeo entre historiadores y arqueólogos del ámbito científico-universitario - de 180 universidades y 30 países cuyas opiniones han generado interesantes reflexiones y debates.

Palabras clave: cultura audiovisual; Plan Bolonia; sociedad de la comunicación; sociedad de la información; TIC (tecnologías de la información y la comunicación); universidad; vídeo; vídeo-entrevista; vídeo-lección; virtualización.

\section{[en] An innovative project in archeology. The use of audiovisual material as a didactic resource in university education}

\begin{abstract}
Learning mechanisms need to be rethought. The physical classroom has become a limited space for the current generation to acquire knowledge and the university has fallen into a bureaucratic trap that hampers academic visibility. The video-lesson, as well as the video-interview, are revealing themselves as two tools of enormous potential, which complement face-to-face classes and stimulate the transfer of content. They also allow an economization of resources in the long term as well as making time invested by professors and students profitable, leaving behind a system like "note-taking" in the classroom. In the present article the infinite possibilities of the use of video in higher education are exposed, as well as the contrasting reaction it is receiving in the university establishment. As a sampling, the acceptance of the use of video among historians and archaeologists from the scientific-university sphere -180 universities from 30 countries - have generated interesting reflections, opinions and debates.

Keywords: audiovisual culture; Bolonia Plan; communication society; Information and Communication Technologies (ICT); information society; video; video interview; video lesson; university; virtualization.

Sumario: 1. Introducción. Estado de la cuestión. 2. El vídeo como alternativa a la clase presencial. 3. La vídeo-entrevista: un género con gran proyección académica. 4. Un proyecto de innovación docente en el área de la arqueología. El poder de la imagen en la transferencia académica. 5. ¿Vídeo versus academia? Encuesta a nivel mundial entre historiadores y arqueólogos. 6. Desafíos para el futuro. 7. Conclusiones. 8. Bibliografía.
\end{abstract}

Cómo citar: Casado Rigalt, D. (2018): Un proyecto innovador en arqueología. El uso de material audiovisual como recurso didáctico en la enseñanza universitaria Complutum, 29(2): 427-450.

Francis Bacon: "el que no aplique nuevos remedios debe esperar nuevos males, porque el tiempo es el máximo innovador. Saber escoger el tiempo es ahorrar tiempo"

\footnotetext{
1 El presente artículo ha sido concebido en el marco del grupo de investigación en ciencias sociales tecnológicas (GICSOT_A-81618894-GI-17/1).

2 Universidad a Distancia de Madrid.
} 


\section{Introducción. Estado de la cuestión}

El recurso más crítico del siglo XXI es el tiempo. El tiempo es nuestra impaciencia. Tan es así que en este nuevo escenario de vertiginosa era digital conceptos como rentabilidad o productividad presiden buena parte de los esfuerzos acometidos por gobiernos, empresas y entes de todo tipo. Vivimos en una urgencia continua, de cambios constantes, fugacidad y transformación. Lo efímero se impone a lo permanente y la cultura de la inmediatez preside la relación del ser humano con su entorno.

En ese contexto resulta comprensible que la sociedad de la información (y por ende la sociedad del conocimiento) se haya convertido en el fenómeno por antonomasia en un universo globalizado. Sin embargo, no es fruto de una evolución lineal. Es el resultado de un proceso que parte de la creación del conocimiento a partir de tres hitos culturales: escritura, imprenta y, recientemente, la comunicación electrónica (Simone 2001). Asistimos a un momento clave definido por la transición entre la sociedad industrial y la sociedad de la información (Fernández 2001: 145). Y como toda transición se requieren necesidades para adaptar las dinámicas a nuevos escenarios. Éste es uno de ellos.

En el plano que aquí nos interesa, el educativo, se requiere de unos mecanismos que no están aún en sintonía con la sociedad del conocimiento. De hecho, "los sistemas de educación preparan a las personas para ocupar un lugar en la sociedad imitando a las fábricas y oficinas de una sociedad industrial' (Fernández Prieto 2001: 145). De alguna manera no hemos superado aún la contradicción señalada por Fernández Prieto, según la cual "las escuelas tal como las conocemos están diseñadas para preparar a las personas para vivir en una sociedad industrial" (Fernández Prieto 2001: 145).

Una de las principales damnificadas por las exigencias de la sociedad de la información es la universidad. En plena eclosión cibernética, la velocidad en la transmisión del conocimiento y el auge de los entornos virtuales están configurando una sociedad interconectada que disuelve fronteras espaciales y sortea barreras físicas (Tünnerrnann 2003: 6; De Pablos 2010: 7-8; Tedesco 2000: 47). La emergencia del conocimiento transfronterizo nos obliga a repensar los objetivos de la educación superior y dar sentido a los catalizadores de la enseñanza. Sin entrar en derivadas epistemológicas, lo cierto es que cada vez son más las voces críticas que señalan a la universidad como un estamento rezagado que debe enfrentar su propia renovación sin perder la esencia de su fundamento: docencia e investigación. La sociedad de la información ha venido para quedarse y el efecto dinamizador de los medios masivos ha provocado que la universidad ya no tenga la exclusividad en la generación del conocimiento académico (Gros y Lara 2009: 224-231). Parece contradictorio que "la democratización del acceso a los niveles más complejos del conocimiento quede confinada, como ahora, al acceso a la universidad" (Tedesco 2000: 75).

Algunos autores han invocado ya a una suerte de "revolución de la cultura docente" (De Pablos 2010: 14) como un proceso necesario para optimizar mecanismos que fomenten el aprendizaje. Conceptos como progreso o innovación son los inspiradores habituales de informes, memorias o estudios llevados a cabo por distintos organismos cuyo objetivo es revisar y redireccionar las políticas universitarias actuales para tender hacia una universidad con vocación de modernidad, calidad y compromiso social ${ }^{1}$ (Gumbau 2006: 22; Herrán 2005: 253). Poco a poco, las instituciones de enseñanza superior "están siendo requeridas para dar respuesta a demandas de formación más flexibles y adaptadas, y a la necesidad de incorporar nuevos sistemas pedagógicos" (De Pablos 2010: 12).

En las casi dos décadas de siglo - y milenio - que llevamos transcurridas, se ha disparado la literatura científica centrada en analizar la relación global de la universidad con el entorno social, así como las debilidades del estamento académico. Sin embargo, muchas de las publicaciones tienen un alto grado de abstracción y tratamiento teórico. Existen pocas visiones o análisis en los que se descienda al detalle de los mecanismos de aprendizaje aplicados en las aulas convencionales, que serán el leitmotiv de este artículo.

El conocido Plan Bolonia ${ }^{2}$, aprobado en 1999, representa el inicio de un proceso de convergencia que viene aspirando a la reforma universitaria en el ámbito europeo y que - tras la Conferencia de Praga de 2001 - sumó a sus objetivos el de lograr una educación transnacional. Una de las críticas más invocadas por sus principales detractores es la excesiva mercantilización (Agís 2008: 190-192). Pero más allá de este debate, llama la atención que por 
ningún lado se incida en la imperante necesidad de que el docente universitario maximice o rentabilice el tiempo invertido en las dos tareas inherentes a su función: la docente y la investigadora.

La educación superior se encuentra ahora en una complicada coyuntura que le hace debatirse entre la fidelidad hacia el formato tradicional (presencial) y la adaptación a las plataformas digitales. Una gran mayoría de universidades ha comenzado a desdoblar las modalidades presencial y a distancia aunque, de momento, se trata de un automatismo para agilizar el contacto profesor-alumno. La brecha existente entre universidades presenciales y online es tal que iniciativas como la Agenda 2030 pretenden generar modelos estratégicos que, desde la construcción de alianzas y el compromiso común, racionalice las actuaciones universitarias.

Uno de los fenómenos resultantes del contexto socio-académico actual es la proliferación del individualismo en las sociedades occidentales (Tedesco 2000: 44). Cada vez es mayor el rango de elecciones que un ciudadano, en el plano social, y un estudiante, en el plano académico, tiene ante sí. La infraestructura tecnológica brinda a los entornos educativos las herramientas necesarias para hacer viable esta educación individualizada y participar en una sociedad del conocimiento que se base en las telecomunicaciones y no en el transporte (Fernández Prieto 2001: 145). De ahí el importante rol desempeñado por las TIC (Tecnologías de Información y Comunicación) en una concepción versátil que flexibilice los cánones de enseñanza-aprendizaje (Salinas 2004: 1; Gros y Lara 2009; Cabero 2007: 5-6). Poco a poco empieza a aceptarse que la aplicación e implementación de las TIC en los sistemas de enseñanza de las universidades son ya indicadores de calidad de las instituciones (Marqués 2008: 10) a pesar de que "dos de cada tres universidades siguen careciendo de un plan de dotación y distribución de recursos humanos relacionados con las TIC que se actualice periódicamente" (Gómez 2016: 14).

Las TIC son consustanciales a la innovación, que es la base de la sociedad del conocimiento y uno de los motores de la globalización (Casas 2005: 3; De Pablos 2010: 13; Gómez 2016: 112-113). La UNESCO, en la declaración mundial sobre la educación superior en el siglo XXI, celebrada en París en 1998, ya asumió que la educación superior debía aco- meter un proceso de profunda transformación digital que atendiera a nuevas realidades y demandas tanto sociales como científicas con la asunción de la "cultura informática" como reto ineludible: "lo que no pueden las instituciones de educación superior, y por ende sus docentes, es negarse o resistirse a la utilización de tales tecnologías (...) y al intercambio académico (...) Tenemos que aprovechar el gran potencial educativo de las nuevas tecnologías" (Tünnerrnann 2003: 17).

Sin embargo, sería un error sacralizar en exceso las TIC, lo que nos abocaría a "una universidad desnaturalizada que progresivamente se aleja de esa aspiración humanista y antropocéntrica inherente a su naturaleza" (Agís 2008: 191-192). Las TIC deben ser un medio y nunca un fin; y su uso debe ir dirigido tanto al aprovechamiento del tiempo como a la asimilación de contenidos académicos a través del recurso tecnológico. De alguna manera, debemos tender a una progresiva socialización de la técnica y no a una tecnificación de la sociedad.

Una de las estrategias más aducidas en recientes seminarios, simposia, coloquios y congresos es la implementación de políticas colaborativas y redes telemáticas de aprendizaje desde el convencimiento de que el conocimiento debe ser difundido y compartido. Incluso hay autores que defienden la implicación de la propia administración en este fomento del espíritu colaborativo (Fernández Prieto 2001: 146). Aumenta paulatinamente el número de profesores que reconocen la ventaja de las universidades online frente a las presenciales a la hora de establecer sinergias que redunden en el enriquecimiento de los procesos didácticos y la dinamización de grupos (Marqués 2008: 3).

Actualmente, las clases impartidas en la universidad presencial incurren, de forma involuntaria, en un fenómeno de privación $\mathrm{u}$ omisión del conocimiento a millones de personas. Es decir, la audiencia se reduce a las decenas de estudiantes que acuden de forma síncrona al aula universitaria. Desde el punto de vista de la inversión educativa es un "desperdicio" que el disfrute de ese conocimiento se limite a un grupo reducido de alumnos.

Si circunscribimos el análisis a la docencia en el ámbito de la Arqueología, y disciplinas afines, detectamos un enorme potencial de propuestas innovadoras que posibilitarían el uso de metodologías activas de enseñanza y aprendizaje; tanto en el ámbito universitario (Vicent 
et alii 2015) como en la educación primaria y secundaria (Fernández Díaz et alii 2014) o en el entorno museológico y patrimonial (Tejado 2005; Rascón y Sánchez 2008; Menéndez et alii 2015; Rivero y Feliu 2017). A día de hoy abunda la literatura científica centrada en resaltar las bondades tecnológicas de la realidad aumentada, la virtualización, la creación de espacios interactivos o el mobile learning. Sin embargo, se echan en falta ideas innovadoras que, desde el pensamiento crítico y la reflexión, mejoren los mecanismos de aprendizaje asumidos en las aulas universitarias donde se forman arqueólogos e historiadores. En las siguientes líneas se propondrán varias estrategias a implantar en entornos universitarios especialmente en el ámbito arqueológico - con la vista puesta en la rentabilidad académica y el aprendizaje autónomo e inclusivo.

\section{El video como alternativa a la clase presencial}

En el arranque de este artículo se subrayaba el valor del tiempo como recurso. Citas como la del escritor y ensayista francés del XVIII Jean de la Bruyére - quien sostenía que "los que emplean mal su tiempo son los primeros en quejarse de su brevedad" - invitan a una profunda reflexión crítica que ha de ser proyectada sobre la enseñanza superior. Todavía en el recién comenzado siglo XXI, el profesor de universidad española (inmerso en un triple frente de funciones docentes, investigadoras y de gestión) está abocado a una progresiva multiplicación de sus tareas ${ }^{3}$. Más allá de las particularidades que presenta el reparto de funciones y la carga laboral en cada una de las universidades del mundo, lo cierto es que existen deficiencias estructurales que merecen ser abordadas.

El modelo vigente en las universidades presenciales es el de aula física como espacio único generador de contenidos académicos. Viene siendo así desde que se fundaron, al calor de las escuelas catedralicias y las llamadas "escuelas de leyes", las primeras universidades europeas $^{4}$ entre los siglos XI y XII (Gómez García 1986: 11-15; Carrasco 2015). Nacieron como corporaciones del saber y la metodología docente recaía entonces en dos formatos de interacción entre profesores y alumnos: la lectio o lección magistral y la disputatio o discusión. Esta última consistía en la exposición de una tesis o planteamiento teórico, a la que seguía un turno de argumentos a favor o en contra por parte de las autoridades en la materia. Se exponían las objeciones pertinentes, la solución de dificultades y las conclusiones; y en estas discusiones, el profesor ejercía de guía y supervisor del proceso (Agís 2008: 186187).

Desde el nacimiento de las primeras universidades occidentales, la lección magistral ha sido, al menos en el ámbito de las humanidades, el modelo más común de técnica de comunicación entre profesor y alumno. En esta modalidad de transmisión de conocimiento el profesor transfiere contenidos académicos de forma síncrona, con el apoyo de recursos - desde el siglo XVIII - como la pizarra, el retroproyector, las diapositivas o los actuales power points. Es decir, el requerimiento de la presencialidad ha sido y es una condición sine qua non para que todo el caudal de datos y experiencias trasladadas por el docente llegue al interlocutor o discente. Tradicionalmente el recurso empleado para registrar la lección magistral ha sido la toma de datos o apuntes por parte del alumno (Espino 2012). La mecánica es sencilla: el profesor diserta y el alumno registra.

La necesidad de perpetuar en la memoria todo el flujo de conocimiento emanado de estas lecciones es la que ha llevado al sistema a implementar recursos que favorezcan la retención de datos. La toma de apuntes ha sido la fórmula más recurrente; la manera más lógica, mayoritaria y eficiente de aprehender todo el caudal académico surgido del aula física y el llamado docente de aula (Fernández Prieto 2001: 145). Sin embargo, el nuevo contexto socio-educativo y los constantes cambios estructurales a los que nos obliga la envolvente sociedad de la información demuestra que la toma de apuntes se está convirtiendo en un procedimiento mecanicista anacrónico, desfasado y, en términos de rentabilidad académica, un hábito improductivo.

El alumno de universidad presencial ha quedado reducido a un autómata, a un escriba de emergencia que actúa contrarreloj. Al tomar apuntes, se convierte en un mero registrador de datos, hoy, o un copista de monasterio, siglos atrás. El lógico afán del estudiante por "dar fe" de la mayor cantidad de información proporcionada por el docente hace recaer la atención del alumno en la mera anotación, convirtiendo la interacción profesor-alumno en lo que en 
los escalafones educativos básicos se conoce como un dictado. Ante este argumento cabría el contraargumento de que el alumno va procesando y reteniendo contenidos mientras escribe. Indiscutible. Y lo justifica aún más el hecho de que las alternativas propuestas al sistema de la toma de apuntes apenas han cuajado en el área de las humanidades. El problema surge cuando las nuevas tecnologías proveen ya de alternativas que mejoran e implementan el sistema tradicional de toma de apuntes.

En general, tanto gobiernos como administraciones y empresas han adecuado sus mecanismos a los nuevos tiempos; no así la universidad, resignada al aislamiento institucional y que sigue basando la transferencia académica entre profesor-alumno en el aula física. Un desfase denunciado por el gurú de la tecnología Bill Gates: "las corporaciones se están reinventando en torno a las oportunidades abiertas por la tecnología de la información; las escuelas también tendrán que hacerlo". Uno de los problemas que lastra la universidad es la excesiva sacralización de sus métodos. Aspirar a la durabilidad de los procedimientos estilados en la universidad se presenta cada vez más complicado. Es ya una quimera, un imposible. Mantener el sistema de la toma de apuntes en la universidad sería equiparable a que las multinacionales siguieran comunicándose por correo postal o que los contribuyentes hiciéramos cola, de nuevo, para presentar la declaración de la renta. Está claro que administrar el tiempo con eficiencia debe ser ya una prioridad para dar sentido a nuestras actividades y expectativas; y la toma de apuntes requiere ser reemplazada por sistemas más viables en términos de transmisión de conocimientos, permanencia, visibilidad y eficacia académica.

El vídeo se está revelando, de momento, como el más eficiente canal de comunicación y transferencia en el ámbito de la enseñanza superior (Pérez Navío et alii 2015). No solo es una forma simbólica y autónoma de representar la información con distintos grados de abstracción de la realidad. Además, contribuye eficazmente a la retención de contenidos y a la visualización o representación gráfica del conocimiento con alto grado de iconicidad, generando incluso "procesos de microcomunicación originales" (Bravo 1998: 32). El vídeo refuerza la recepción de contenidos de forma dual (imagen+voz), una circunstancia favorecedora desde el punto de vista mnemotécnico.
Como contenido académico su permanencia y accesibilidad (puede alojarse, si se opta con dejarlo en abierto, en el canal youtube ad infinitum) está garantizada a menos que en los próximos años alguna maniobra empresarial desencadene una privatización inesperada. De alguna manera, la implantación del vídeo potenciaría un concepto innovador de aula, como espacio multimedial, que en alguno de los casos concretos ha sido bautizado como Polimedia (Infante Moro et alii 2010: 5-7) y que hunde sus raíces en los primeros intentos de poner en marcha canales educativos y llevar a cabo producciones de consumo académico (Salinas 1995).

Uno de los handicaps severos de la clase presencial, frente a las bondades del vídeo, es que el recuerdo o registro que deja en la memoria de un estudiante una clase presencial está expuesto a la pérdida progresiva. Ya de por sí el apunte (tomado por el alumno) no registra la totalidad de lo expuesto por el profesor. $\mathrm{Si}$ el profesor proyecta diapositivas o expone gráficos, esquemas, fotos, mapas, planos, etc. el alumno no podrá registrar esos grafismos de forma fidedigna. Quedarán en su memoria solo temporalmente y sin las precisiones ni detalles que toda representación gráfica requiere en su interpretación. Un vídeo permite cuantas visualizaciones queramos, sin las exigencias geotemporales de sincronía que exige el aula física.

Pongamos por caso la exposición de diapositivas ó los ya clásicos power points, con varias decenas de imágenes, en un aula física por parte del profesor. En condiciones normales sería necesario contar con aulas repletas de alumnos superdotados que registraran todas y cada una de las imágenes proyectadas. Los apuntes tomados por el alumno en ningún caso pueden suplir la fidelidad de la imagen visualizada en un vídeo. El cerebro humano difícilmente puede retener (y menos aún tras el paso del tiempo) todos los detalles y matices visuales contenidos en el caudal de imágenes expuesto en una clase presencial. El vídeo permite volver a visionar cuantas veces sea necesario e incluso saltar con el cursor al tramo del vídeo que nos interesa reproducir, sin necesidad de escuchar la sesión entera. En términos comparativos, la capacidad de retención memorística, en el caso del vídeo, es muy superior a la de una clase presencial (Bravo 1998: 5).

Las sociedades del siglo XXI tienden a imponer fórmulas en las que el aprovechamiento 
del tiempo es una prioridad. El aula física (lecciones en directo) implica y exige convocatorias masivas y sincrónicas. En muchos de los casos, profesores y alumnos residen en otras ciudades y están obligados a una inversión de recursos económico-temporales que no siempre pueden permitirse. El vídeo no implica, en ningún caso, esos requerimientos espacio-temporales y por eso "debería ocuparse de aspectos de la realidad que son dificilmente accesibles para el profesor en el aula" (Salinas 1995: 110).

Existe, además, otro argumento de peso a favor de la implantación del vídeo como alternativa. Muchas de las disciplinas impartidas en la universidad están poco expuestas a la necesidad de actualizar sus temarios. En el área de humanidades existen áreas de conocimiento - filosofía, historia, literatura, etc. - que no experimentan excesivos cambios en sus contenidos. Más allá de bibliografía actualizada, celebración de nuevos congresos, eventos o publicaciones que van viendo la luz, lo cierto es que un porcentaje elevado del contenido impartido en el aula física, año a año, se repite. Deberíamos contemplar la posibilidad de salir de ese asumido bucle académico consistente en lecciones que se replican anualmente y cuyo registro queda reducido a los clásicos apuntes. El vídeo contempla, además, la posibilidad de "alimentar" su contenido matriz con textos adjuntos, comentarios, matices, bibliografia, etc.

Desde el punto de vista del retorno académico, si el vídeo sustituyera aquellas lecciones que experimentan pocos cambios con el paso del tiempo, el profesor quedaría liberado de repetir nuevamente la misma lección (ya grabada) y podría invertir ese tiempo en investigación, ejercicios prácticos, tutorías, debates u otro tipo de fórmulas académicas alternativas.

Uno de los problemas de los vídeos, a día de hoy, es el recelo de parte del estamento académico contra un formato sobre el que recaen ciertos prejuicios. Todavía hay profesores que desconfían del vídeo, al que etiquetan de "contenido sospechoso" por su condición audiovisual. Sobrevuela aún un sentimiento de rechazo y para algunos docentes sigue siendo recurrente el argumento de la artificiosidad antiacadémica o el efectismo intrascendente, dada la naturaleza audiovisual del formato.

Sin embargo, es un ejercicio saludable "desmitificar la importancia asignada al medio en si" (Ofelia 2012: 74) porque un vídeo no es nocivo per se como documento. Dependerá exclusivamente de la calidad de su contenido y de la inspiración del docente a la hora de documentar, elaborar, grabar y editar el vídeo en cuestión. Otro valor añadido del vídeo académico es la retroalimentación e interacción que implica su uso, además de su exposición frente a otros colegas ya que "contribuye a analizar una de las profesiones más desconocidas porque ningún docente sabe cómo trabaja otro dentro de su aula (...) ayuda a conocer y comprender tanto al profesorado como los contenidos" (Pérez Navío et alii 2015: 52).

Nadie discute que producir un contenido de calidad implica una inversión considerable de tiempo y dinero, además de una infraestructura técnica: plató, realizadores, editores, etc. Actualmente hay pocos vídeos en la red con suficientes garantías de calidad académica como para nutrir el temario de una asignatura universitaria. Pero la transformación digital de las universidades es un proceso inevitable que ya está en marcha. En cuanto a la planificación del tiempo invertido en el aula, existe cierto consenso en aceptar el principio axiomático de que cada hora empleada en planear las diferentes actividades ahorra de tres a cuatro horas de ejecución y, a largo plazo, se obtienen mejores resultados.

Se prevé, a medio o largo plazo, un contexto de mayor aprovechamiento de los recursos disponibles en el que el vídeo será una de las soluciones adoptadas para propiciar un escenario académico abierto, dinámico y rentable. Dentro de la fase experimental en la que nos encontramos cabe anticipar una cierta reconversión por la cual la educación superior acabará digitalizando los contenidos académicos con el fin de que el alumnado acabe disponiendo de materiales accesibles en la red. De alguna manera, deberíamos aspirar a nuevas formas o canales de comunicación y transferencia de contenidos académicos, más aún cuando los nativos digitales y la llamada "generación Z" van eclipsando, poco a poco, a todos aquellos que representamos la "generación puente" o los llamados "emigrantes digitales". Es cierto que los profesores de universidad e investigadores van progresivamente asumiendo la importancia de divulgar trabajos científicos en redes sociales bajo el convencimiento de que "divulgar no supone infantilizar o vulgarizar lo que se comunica" (Salinas 1995: 107). Plataformas como Facebook o LinkedIn se están convirtiendo en dinamizadoras de la actividad científico-universitaria, aprovechando el 
efecto multiplicador de sus publicaciones y la viralización de las noticias compartidas. Sin embargo, sigue habiendo una especie de "cortafuegos" entre lo científico y divulgativo, que debería matizarse para aquellos contenidos de contrastada valía científica. Reina todavía un cierto caos y la ausencia de filtros supone un riesgo para la correcta transferencia científico-académica.

Debe tenerse en cuenta que el paradigma del aprendizaje se ha visto alterado de forma sustancial. Asumir cambios "significa remover barreras y promover la autonomía del que aprende" (Casas 2005: 6). Nuestros padres vivieron décadas de aprendizaje lento y progreso ralentizado. Los métodos, las sociedades.... todo cambiaba lentamente y sin embargo las nuevas generaciones (los llamados nativos digitales) avanzan en un contexto de crecimiento y aprendizaje exponencial. Todo evoluciona y se renueva rápidamente: nuevas tecnologías, nuevos sistemas de información, nuevos códigos de relaciones sociales. Y en medio del engranaje está el alumno, cada vez más exigente (Marqués 2008: 12; Gros y Lara 2009: 235); con todos los nutrientes que ofrece la red pero sin el criterio necesario para cribar el gigantesco magma de información a su alcance.

En el campo que nos interesa, Arqueología, el formato audiovisual presenta un enorme recorrido, sobre todo tras la eclosión de las recreaciones virtuales, la realidad aumentada y otros recursos que favorecen los procesos cognitivos (Vicent et alii 2015: 85-93; Rivero y Feliu 2017). La implantación del vídeo propiciaría una nueva herramienta de diálogo académico destinada a "fomentar una comprensión global de la historia desde la sensorialidad, el pensamiento y la emoción" (Vicent et alii 2015: 86). Hasta la fecha cabe reseñar algunas iniciativas audiovisuales promovidas en universidades norteamericanas en las que han experimentado con la creación de escenarios arqueológicos de diferentes épocas y latitudes geográficas (Vicent et alii 2015: 91-92).

\section{La vídeo-entrevista: un género con gran proyección académica}

En los últimos tiempos vienen acometiéndose interesantes avances en un área de conocimiento de nuevo cuño: la neuroeducación. Bajo el aforismo de que "no hay razón sin emoción", reputados investigadores como Francisco
Mora (doctor en medicina y experto en neuroeducación) inciden en la necesidad de desarrollar estrategias educativas que conmuevan al discente para estimular el aprendizaje. Según el citado investigador, el profesor y la emoción son los ejes fundamentales de toda enseñanza y "la curiosidad, lo que es diferente y sobresale en el entorno, enciende la emoción. Y con ella, con la emoción, se abren las ventanas de la atención, foco necesario para la creación de conocimiento" (Mora 2013: 73). La obra de Mora es un canto al aprendizaje a partir del estímulo y desde las profundidades de la esencia humanista, compartiendo el convencimiento de que "los profesores más brillantes aman las disciplinas que enseñan, respetan y aprecian a los estudiantes; tienen la habilidad y la voluntad de conectar la disciplina y los estudiantes" (Marqués 2008: 11). Mora sostiene que sin emoción no hay memorización sólida; y tampoco pensamientos ensamblados y coherentes. En cierto modo, Mora se enmarcaría en esa corriente que en los últimos años está reforzando los enfoques humanistas en el ámbito de la enseñanza, siguiendo recomendaciones presentadas en la Declaración Mundial sobre Educación Superior en el siglo XXI (Herrán 2005: 228).

Cada vez son más los docentes que desarrollan recursos didácticos encaminados a conmover al discente con el fin de despertar en él, desde la experimentación, la curiosidad necesaria para optimizar el proceso de aprendizaje, maximizar su motivación (Bravo 1998: 6) y desarrollar el rol activo del alumno. Este perfil de "docente inquieto" persigue una dinámica de clase más amena, participativa, receptiva y práctica.

En las primeras páginas de este artículo ya fue abordada la vigencia de la lección magistral, impartida en el aula física, como fórmula de transmisión de conocimiento en el ámbito universitario. En el epígrafe 2 ha sido defendida la idoneidad de la vídeo-lección como alternativa a la lección magistral. Pero existe otra alternativa audiovisual que podría traer aire fresco a los mecanismos de transferencia académica dentro de la comunidad universitaria. Se trata de la vídeo-entrevista: un género infraponderado y tradicionalmente vinculado al entorno periodístico o el mundo de la comunicación.

Una contribución notable de la entrevista es que el temario se enriquece con visiones ajenas, de especialistas en subáreas, que refuer- 
zan y amplían el conocimiento del profesor, rompiendo además con la monotonía de un aula conducida siempre por el mismo docente. Asimismo, desde el punto de vista mnemotécnico favorece la retención de datos y la capacidad evocadora el hecho de que la información proceda de varias voces o fuentes o, de alguna manera, se rompan las normas o el ritmo como en el llamado "efecto Von Restorff" (Sebastián 2016: 21).

Es habitual que los profesores de las asignaturas impartidas en las universidades no sean especialistas en todas las materias que han de impartir. En la gran mayoría de los casos, la tesis doctoral defendida por un doctorando (futuro profesor) difiere, en contenido y especialidad, de las asignaturas impartidas. Lo más común es que el contenido de una asignatura incluya áreas de conocimiento tan diversas y distantes como para que sea conveniente plantearse la aportación de visiones ajenas proporcionadas por otros colegas. Nutrir un aula con vídeo-entrevistas - en las que el profesor de la asignatura interactúa con otro especialista optimizaría los recursos y dotaría a los alumnos de una herramienta didáctica novedosa; al menos subutilizada en entornos de educación superior distintos al periodismo o la comunicación audiovisual. Además, una entrevista (que puede derivar ocasionalmente hacia el formato debate) se convierte en una apuesta dinamizadora, basada en la retroalimentación y en la interacción de dos o más profesores. Otro de los beneficios académicos que proporciona la entrevista es que los profesores participantes crean sinergias académicas, se familiarizan con temas en los que no son especialistas e incorporan tanto conocimientos como contactos con otros colegas.

Muchos de los manuales y libros de referencia de las asignaturas impartidas en la universidad han sido concebidos como obras colectivas en las que varios especialistas contribuyen con diferentes capítulos. ¿Por qué no reproducir ese mismo formato de contribución colectiva de especialistas en el caso de un aula, nutriéndola de links (vídeo-entrevistas) en los que se aportan visiones variadas de especialistas? El reto merece la pena, más allá del celo de la autoría que todavía impera. Supondría cambiar la norma académica y aceptar una nueva concepción de aula abierta en la que se estilara el préstamo de conocimientos y el intercambio de contenidos académicos entre docentes de distintas instituciones universita- rias. De esta forma, en las vídeo-entrevistas el profesor ejercería de orientador del aula: una suerte de intermediador (o facilitador de información) entre los alumnos y el especialista invitado. En definitiva, fórmulas que combinen las TIC con nuevas destrezas y conocimientos (Salinas 2004: 3).

De alguna manera, los mecanismos docentes en la educación superior carecen de esa transversalidad enriquecedora - a la que apeló en su día Ortega y Gasset - y que no pocas veces ha sido denostada por el estamento científico y universitario: “Los 'expertos' (...) son personas que conocen cada vez más un sector cada vez más pequeño de la realidad. Son 'sabios' incultos, exponentes de lo que Ortega llamará la 'barbarie del especialismo" (Agís 2008: 189-190).

Actualmente, buena parte del esfuerzo docente se centra en el diseño curricular, lo que redunda en preocupantes contradicciones desde el punto de vista del aprendizaje y la formación (Herrán 2005: 232). Se incurre a menudo en la inoperancia por culpa de un inexistente tejido curricular básico que promueva una enseñanza más formativa, ecléctica y transdisciplinar. Además, no existe suficiente vocación transversal en el desarrollo de proyectos docentes que tiendan a la supradisciplinariedad. Seguramente sería más beneficioso para todos si desde la perspectiva de la enseñanza y la investigación se emprendieran proyectos y procesos supradisciplinares (multi, inter, trans y metadisciplinares) con un espíritu más integrador basado en la transversalidad didáctica (Herrán 2005: 239, 244-245). La transversalidad universitaria debería ser entendida como aquella que "tiene como origen y destino la formación para la vida", además de "un recurso metodológico e intrínsecamente motivador" (Herrán 2005: 245-247).

La vídeo-entrevista - como modelo innovador - encajaría con una propuesta o modelo tendente a la ductilidad; el intercambio entre profesores y estudiantes; la apertura al diálogo, la profundización y la evaluación continua. Esta propuesta basa su dinámica en la existencia de universidades, facultades y departamentos transdisciplinares. Para ello sería necesario resolver un proceso de convergencia que satisficiera una transición coherente con zonas de solapamiento y espacios de autonomía. En ese nuevo contexto, debería garantizarse la flexibilidad y creatividad suficientes como para dejar atrás el modelo "submarino" en el que 
vienen primando los compartimentos independientes y herméticamente cerrados (Herrán 2005: 247-254). En el ámbito arqueológico viene acometiéndose en los últimos años la generación de espacios colaborativos que "aprovechan la intercomunicación que se establece en la web 2.0, buscando el rigor a través de la inteligencia colectiva, para lo cual es necesario una comunidad virtual activa muy numerosa" (Rivero y Feliu 2017: 329). La serie "Arqueoudima", expuesta a continuación, es buen ejemplo.

\section{Un proyecto de innovación docente en el área de la arqueología. El poder de la imagen en la transferencia académica}

La asunción de la cultura audiovisual es una evidencia incuestionable en la sociedad del siglo XXI. Las nuevas generaciones han nacido y crecido en un entorno presidido por el consumo masivo de contenidos en los que la imagen es una parte esencial del mensaje. Eso implica reconocer que la capacidad evocadora de una fotografía o una imagen en movimiento (vídeo) han convertido a la representación gráfica en una poderosa arma de comunicación. La percepción se realiza por la vista y el oído simultáneamente y "las vinculaciones de imágenes y sonidos son tales que cada uno contrae relaciones con el otro por armonía, complementariedad, refuerzo o contraste" (Cebrián 1995: 54). Lo saben los publicistas, los comunicadores y todos aquellos profesionales cuyos sectores dependen de la efectividad del discurso. De ahí la importancia de conocer la receptividad de las personas ante estímulos externos. Un dato demoledor: el $80 \%$ de las presentaciones profesionales se hacen con medios visuales o audiovisuales (Bravo 2005: 6). Gracias a la imagen, el ser humano puede desarrollar nuevos lenguajes y generar procesos mentales superiores en los que la presentación de la información se lleva a cabo por diferentes códigos, de forma más flexible y con la posibilidad de utilizar diferentes estructuras narrativas (Cabero 2007: 8-9).

Existe cierto consenso a la hora de clasificar a las personas según el tipo de aprendizaje: visuales, auditivas y kinestésicas o cinestésicas. Cada uno de nosotros posee unos canales sensitivos para entender el mundo e interaccionar con el entorno pero siempre prevalecen unos canales sobre otros. Las personas visuales priorizan la observación, la imitación, los gestos y las pocas palabras; y "cuando recuerdan algo lo hacen en forma de imágenes" (Navarro 2016: 26). Las auditivas dan prioridad al aprendizaje secuencial a través de la conversación o la música. Y las kinestésicas son personas sensitivas que se decantan por el aprendizaje a través de las emociones; son refractarias a los excesos teóricos o el abuso del texto. Los límites entre estas tres categorías son lo suficientemente difusos como para establecer categorizaciones rígidas. De hecho, en los procesos de aprendizaje intervienen otros factores esenciales: interés y motivación del alumno, la diversidad cognitiva del aula, las capacidades y necesidades personales del discente; $y$, por último, su procedencia cultural (Navarro 2016: 28).

No todas las disciplinas impartidas en la universidad requieren de la imagen en la transferencia de contenidos académicos. Áreas como el derecho, por ejemplo, pueden ser abordadas sin necesidad de representaciones simbólicas ni imágenes. Pero la mayoría de materias impartidas y estudiadas en el ámbito de la enseñanza superior necesitan de aparato gráfico. Partimos de la premisa de que las imágenes facilitan la representación mental de conceptos, favoreciendo así que imagen y texto se complementen en la misma coordenada memorística. Además, el grafismo es "una forma sencilla y rotunda de expresar un resultado. Tiene un efecto sobre el recuerdo de la audiencia muy superior al que ofrece un texto escrito" (Bravo 1998: 26). Sin embargo, la eclosión de la imagen y la representación simbólica - como rápidas y eficaces fórmulas de comunicación - no está teniendo la misma acogida en todos los estamentos o sectores. En el ámbito que nos interesa ahora (historia y arqueología, dentro del entorno universitario) el alumno se nutre de grafismos - fotografías, vídeos, reconstrucciones, mapas, planos, dibujos, plantas, etc. - a través de su acceso a material publicado en papel (manuales, artículos y libros), o bien sesiones de power points o diapositivas expuestas en el aula por parte de los docentes. Uno de los problemas del aprendizaje en áreas de conocimiento como la Historia o la Arqueología es que requieren un alto grado de abstracción e imaginación, pero afortunadamente se ve compensada esta limitación con la existencia de otros recursos (Vicent et alii 2015: 85).

El componente visual en el aprendizaje de la arqueología, la historia antigua o, incluso la 
historia del arte, está tan presente que la necesidad de nuevos detalles fotográficos, imágenes en movimiento tomadas desde drones, $3 \mathrm{D}$, planos, mapas, recreaciones o entornos inmersivos está provocando una demanda progresiva de grafismos y virtualización por parte de universidades, centros científicos, empresas e incluso museos (Rascón y Sánchez 2008; Tejado 2005; Rivero y Feliu 2017). Lo que se reivindica, en este artículo, es un "hermanamiento de las disciplinas histórico-arqueológicas con la imagen"; la imagen como generadora de una representación gráfica. La necesidad de implementar la vertiente visual de la arqueología en los entornos académicos redobla la idoneidad de poner en marcha iniciativas que potencien la virtualización del patrimonio histórico-arqueológico y su difusión científica a partir de ambiciosos proyectos como el caso de la "Society of American Archaeology's Open Science Interest Group (OSIG)"5. En términos globales, las prestaciones brindadas por las nuevas tecnologías proporcionan un potencial desaprovechado hasta la fecha por historiadores, en general, y arqueólogos, en particular. Además, late de fondo la conveniencia de que un profesor se convierta, en cierto modo, en "divulgador de la ciencia" cuando comparte las clases impartidas gracias a la producción de vídeo-lecciones o vídeo-entrevistas. De hecho, el rol divulgador del profesor universitario debería ser consustancial a su función docente; a pesar de lo cual el debate generado en torno a la función divulgadora del docente sigue dividiendo al estamento universitario.
Como ya se ha advertido en páginas anteriores, el vídeo es una solución viable para compensar la escasez de material audiovisual producido por el profesorado universitario. La serie Arqueoudima ${ }^{6}$ es buen ejemplo de proyecto docente innovador a modo de serial, con dinámica de entregas periódicas, concebido con rigor científico. Tiene, entre sus objetivos, servir de contenido académico al alumno universitario explotando, al mismo tiempo, las infinitas posibilidades visuales de la arqueología. Se graba y produce en el plató y estudios de una universidad (cuyo nombre se omite por motivos de anonimato) desde 2014; y, hasta la fecha, lleva producidos 21 capítulos que incluyen vídeo-lecciones y vídeo-entrevistas. Aspira, además, a ejercer de heraldo arqueológico global para un público ya iniciado en temas arqueológicos y con un nivel alto de inquietud cultural. Arqueoudima pretende ser un espacio en el que se traten en profundidad - con material audiovisual propio y de alta calidad - asuntos que jamás tendrían acogida en medios generalistas - radio, televisión, prensa escrita - porque la "tiranía de las audiencias" y la publicidad obligaría a rebajar el nivel o tratamiento de los temas para hacerlo más accesible al gran público.

La serie Arqueoudima, dirigida a alumnos de universidad y profesionales del sector, ha sido planteada como un proyecto de innovación docente en el área de la arqueología. La producción incluye dos formatos: vídeo-lección y vídeo-entrevista. Cada capítulo versa sobre un tema previamente seleccionado por su trascendencia científico-académica.
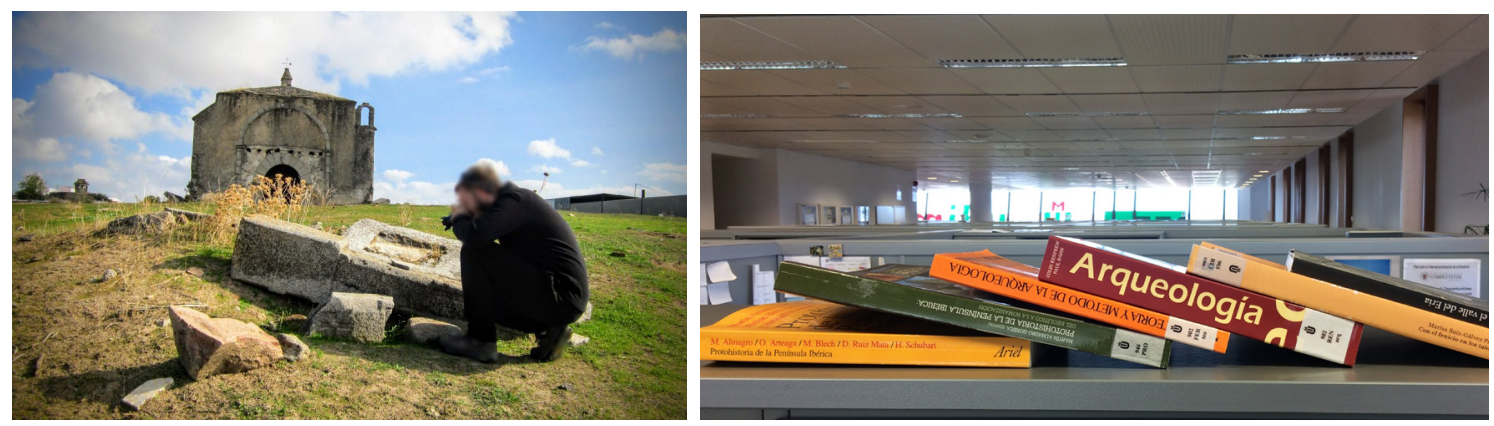

Figura 1. Fases de documentación fotográfica y bibliográfica. 
En una primera fase, el productor de la serie (autor del guión y la idea original) ha procedido a la documentación gráfica (tomas fotográficas o secuencias de vídeo grabadas con cámara profesional CANON) en museos, yacimientos arqueológicos, centros científicos

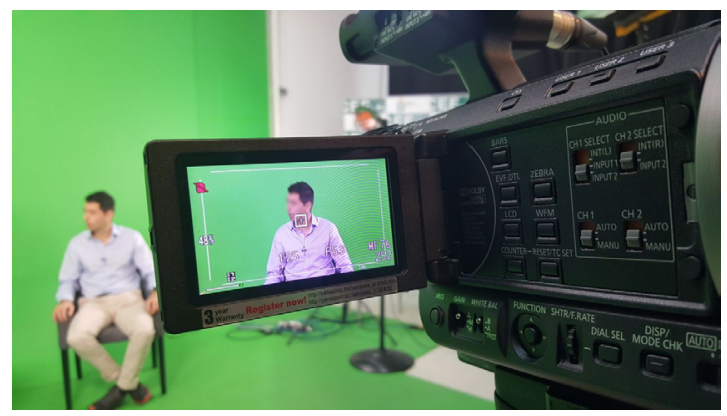

o bibliotecas especializadas, tanto nacionales como internacionales (figura 1). En la siguiente etapa se ha llevado a cabo un rastreo y cotejo bibliográfico a partir de la literatura científica publicada: nutriente básico del contenido a tratar (figura 1).

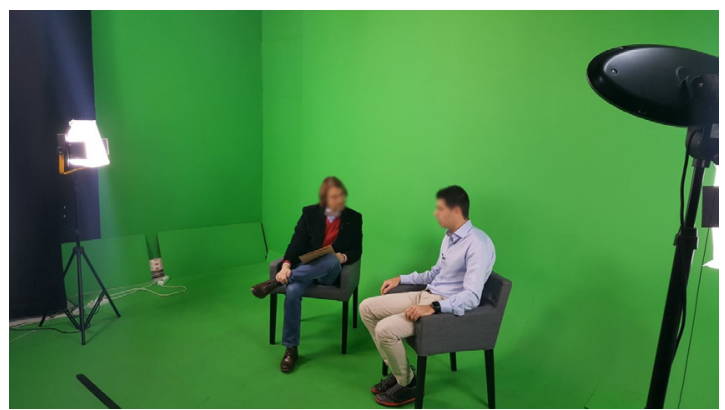

Figura 2. Fase de grabación en plató profesional. Empleo de escenarios virtuales ó técnica croma.

Una vez guionizado el capítulo, el conductor de la serie ha materializado la grabación del vídeo, en el plató de la universidad, con ayuda de realizadores profesionales (figura 2). Gracias a la técnica empleada (croma) se ha logrado una mayor versatilidad de escenarios virtuales, así como un alto grado de definición $\mathrm{y}$ detalle en la reproducción de imágenes o secuencias de vídeo. Todos los episodios han sido editados y posproducidos con el objetivo de perfeccionar el acabado y la sincronía entre el discurso del conductor del programa y los grafismos expuestos (figura 3). El tono y el tratamiento de los vídeos producidos es netamente académico y se ha priorizado el discurso histórico, la novedad científica y el análisis iconográfico frente a otros criterios. La totalidad de los vídeos producidos cuenta con un repositorio de bibliografía actualizada, expuesta al final de cada capítulo.

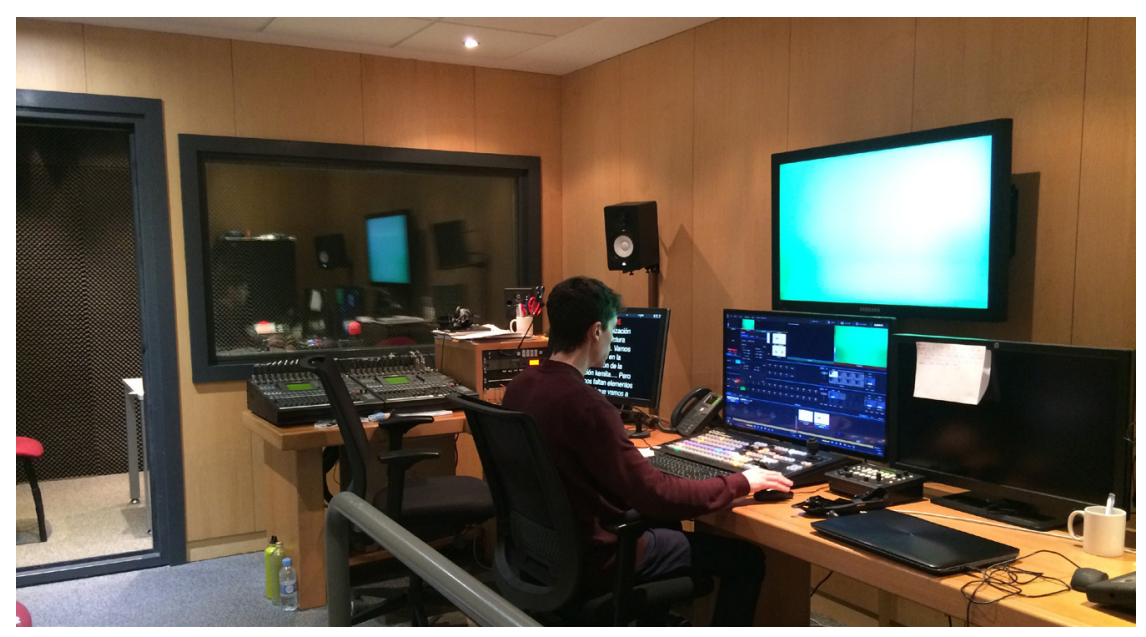

Figura 3. Fase de edición y posproducción en estudio profesional.

En el caso de las vídeo-entrevistas, el procedimiento arranca en un primer contacto con expertos a través de redes profesionales (LinkedIn) o correo electrónico, con el fin de consensuar el asunto tratado. El resto de fa- ses son comunes al procedimiento seguido en las vídeo-lecciones; y el proceso solo difiere en que el especialista invitado habitualmente aporta el material gráfico, que será empleado en la producción de la vídeo-entrevista. 

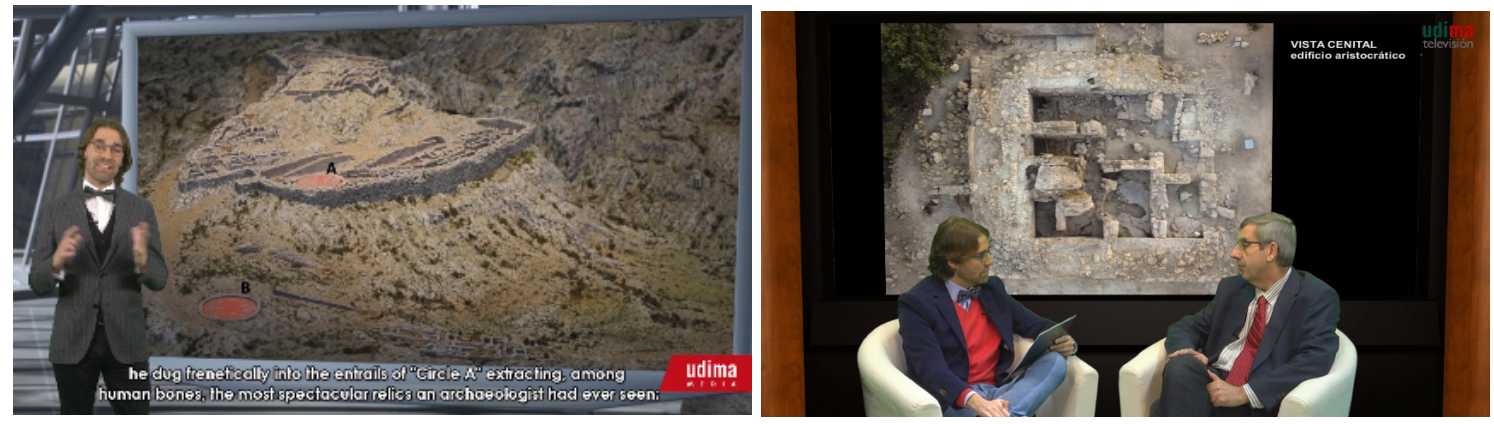

Figura 4. Ejemplos de vídeo-lección y vídeo-entrevista de Arqueoudima, ya disponibles en youtube.

\section{5. ¿Vídeo versus academia? Encuesta a nivel mundial entre historiadores y arqueólogos}

El presente artículo, así como el proyecto de innovación docente, nace del entusiasmo y la convicción de que el conocimiento debe ser compartido y difundido. Pero la aceptación del formato audiovisual, por parte del profesorado universitario, es un proceso lento y discontinuo que no afecta por igual a todas las áreas de conocimiento. Como herramienta para transferir contenidos académicos, la amplia mayoría de los alumnos universitarios ${ }^{7}$ se declara partidaria del material audiovisual por las múltiples ventajas y comodidades que supone recurrir a este tipo de formatos. Sin embargo, la respuesta del profesorado universitario frente al vídeo es dispar. Resulta necesario conocer la acogida de los formatos audiovisuales entre el estamento docente recabando opiniones de manera individualizada. Para ello se ha procedido a elevar una encuesta ${ }^{8}$, a nivel mundial, con el fin de poder sondear opiniones que puedan resultar concluyentes.
El sector elegido ha sido el formado por arqueólogos, especialistas en Historia Antigua y disciplinas afines, áreas de conocimiento humanista en las que la imagen y el grafismo tiene una especial relevancia. De hecho, con tal objetivo se ha adjuntado un ejemplo de vídeo-lección, producida y guionizada por el autor de este artículo, que lleva por título " $\mathrm{el}$ Círculo A de Micenas. Grave Circle A in My-

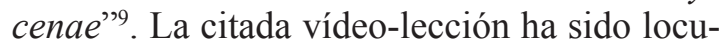
tada en castellano e incluye subtítulos en inglés para favorecer la comprensión de arqueólogos e historiadores foráneos encuestados.

En términos globales, la citada encuesta ha sido enviada a 953 profesores e investigadores españoles, correspondientes a 46 universidades $^{10} \mathrm{y}$ - a modo de muestreo - a 3 centros de estudios y de investigación españoles ${ }^{11}$. En lo que respecta a instituciones extranjeras, la encuesta ha sido remitida a 2.417 profesores que imparten docencia en 138 universidades ${ }^{12}$. Asimismo, han sido consultados 312 investigadores pertenecientes al personal de 25 centros científicos e instituciones ${ }^{13}$.

\begin{tabular}{|l|c|c|}
\hline & ESPAÑA & RESTO DEL MUNDO \\
\hline Número de universidades encuestadas & 46 & 138 \\
\hline Número de profesores universitarios encuestados & 953 & 2.417 \\
\hline $\begin{array}{l}\text { Número de instituciones y centros científicos en- } \\
\text { cuestados }\end{array}$ & 3 & 25 \\
\hline Número de investigadores encuestados & 130 & 312 \\
\hline
\end{tabular}

Figura 5. Datos globales de la encuesta. 
La participación ha sido moderada. En total han respondido 192 encuestados sobre las 3.812 encuestas enviadas. Es decir, un 5,03\% de encuestas respondidas. Un guarismo previsible, en términos porcentuales, si atendemos a la acogida standard de las encuestas online ${ }^{14}$ (Yetter \& Capaccioli 2010; González-Peña et alii 2017: 83) pero suficientemente representativo como para emitir valoraciones concluyentes, en términos absolutos. Más allá de la lluvia de encuestas a la que estamos expuestos en estos tiempos de hipercomunicación cibernética, que explicaría el hartazgo y consiguiente renuncia por parte del potencial encuestado, la primera conclusión desprendida de este dato invita a sostener que reina una cierta indiferencia aún en el estamento académico-científico ante la posibilidad de que el vídeo se postule como alternativa (o complemento) a la presencialidad. En ningún caso, la encuesta plantea la eliminación de la presencialidad, a pesar de lo cual abundan las opiniones, emitidas tanto por profesores/investigadores foráneos como españoles, en las que se presenta el vídeo como un quebranto de la interacción entre profesor y alumnos o, directamente, como un recurso que limita la intervención o la participación activa: "sin la interacción personal con el profesor y otros estudiantes, la visualización de vídeos es sólo un acto de entretenimiento educativo" (profesor/a universidad estadounidense) ${ }^{15}$.

Entre los comentarios de los encuestados son habituales expresiones anglosajonas refractarias al vídeo que reclaman el "compromiso personal con los estudiantes" o el "face-to-fa$c e$ " (profesor/a universidad estadounidense) ${ }^{16}$, "contacto diario entre la facultad y los estudiantes" (profesor/a universidad estadounidense $)^{17}$, "contacto personal entre profesores y estudiantes" (profesor/a universidad austríaca) ${ }^{18}$, "relación directa entre profesor y estudiantes" (profesor/a universidad italiana) ${ }^{19}$; o comentarios escépticos con la implantación del vídeo como que "los vídeos desincentivan la lectura de libros y artículos" (profesor/a universidad española) ó "se pierde el factor humano de las clases presenciales y la interacción directa" (profesor/a universidad española).

Pero lo cierto es que esa pretendida "magia" o interacción, invocada por un sector del profesorado, no se ajusta del todo a la realidad. Forma parte de un discurso enlatado, un argumento falaz. En un aula de universidad el profesor se dirige a un número indeterminado de alumnos (pongamos por caso, cien) cuyas eda- des habitualmente oscilan entre los 18 y los 23 años. Es decir, la contribución de un alumno de esa edad al contenido académico trasladado por el profesor es poco representativa, más allá de las dudas expuestas que pudieran ser de interés para otros estudiantes, porque el alumno asistente al aula no cuenta con bagaje científico-académico suficiente como para generar conocimiento. Distinto es el seminario, los cursos de doctorado (ya extintos en España), el congreso o todos aquellos simposia basados en la interacción científica entre iguales. Pero ni siquiera para este segundo caso - congresos, simposia, mesas redondas, seminarios, etc. - es incompatible el vídeo. Aunque se requieran más recursos y medios técnicos (varias cámaras en una misma sala) registrar las distintas intervenciones o interacciones es posible; lo que nos llevaría a derrocar el viejo tópico de que el vídeo no permite interacción.

El único supuesto que no puede satisfacer el vídeo es la sincronía. Efectivamente no es posible intervenir en directo ("un video no puede responder dudas de alumnos" (profesor/a de universidad italiana $)^{20}$ porque el vídeo queda como una "forma pasiva de aprendizaje" (profesor/a de Reino Unido) ${ }^{21}$; pero siempre estará disponible y sobre él se podrán interponer comentarios ad hoc, sugerencias, objeciones o plantear discusiones de forma sosegada sin limitaciones de tiempo o espacio.

El respeto reverencial al aula física, como espacio generador de conocimiento, evidencia una visión centrípeta de la universidad en la cultura occidental. Tradicionalmente la universidad ha desempeñado el rol de institución productora del conocimiento y depositaria del saber. Sin embargo, la universidad presencial, al menos en los grados universitarios de perfil humanista, arrastra contradicciones de base que han de ser replanteadas. En general, la realidad dista mucho de ese pretendido y aducido dinamismo en las aulas. Los temarios están lo suficientemente ajustados como para que el docente no disponga de excesivo margen como para priorizar la interacción sobre la impartición del temario de la asignatura con dinámica de lección magistral. De ahí que algunos profesores planteen ya el empleo del vídeo "dadas las apreturas de los programas y como apoyo a la docencia, sustituyendo razonablemente la falta de prácticas en laboratorio, por culpa del excesivo número de alumnos y la escasa importancia que dan las autoridades académicas y los programas docentes a eso que, impunemente, 
denominan excelencia" (profesor/a de universidad española). Y volviendo a la tan recurrida interacción del aula, no hay argumento que sostenga la imposibilidad de registrar en vídeo la participación de los discentes. De hecho, la red contiene no pocos vídeos en los que los intervinientes en un congreso, mesa redonda, aula masificada o symposium interaccionan, alternan el turno de intervención y exponen discusiones de tipo académico-científico de forma activa.

La sumisión al tópico sigue teniendo un efecto nocivo sobre la comunidad científica. De hecho, la desconfianza hacia lo audiovisual condiciona aún opiniones que proscriben el vídeo: "el problema surge en la calidez y validez cientifica del material que proporciona el vídeo, la manipulación y capacidad de subjetivizar que puede contener este tipo de materiales. Hay que trabajar el tema de la calidad cientifica, la objetividad y la capacidad crítica en y para con estos materiales" (profesor/a de universidad española). Todavía hay investigadores y profesores que, de forma inconsciente, asocian el vídeo al preciosismo ("la tendencia a exagerar la importancia de las imágenes" 22 (profesor/a de universidad austríaca) y a la divulgación (" $p o$ dría ser atractivo para informar a personas del ámbito no académico" 23 (profesor/a de universidad austríaca); dos presupuestos, nacidos del prejuicio, que contrastan con el entusiasmo y acogida al vídeo por parte de un buen número de docentes e investigadores para los que el nuevo formato audiovisual es perfectamente compatible con el rigor: "los vídeos son herramientas útiles en pedagogía y existen muchas razones para emplearlos si éstos son relevantes e intelectualmente rigurosos" 24 (profesor/a de universidad estadounidense), "un uso apropiado de las video-lecciones es una opción efectiva para ayudar a los estudiantes" 25 (profesor/a de universidad de Reino Unido), "los vídeos tienen un papel importante que desempeñar en el aprendizaje"26 (profesor/a de universidad de Reino Unido). En definitiva, y como ha podido constatarse en un buen número de opiniones procedentes del ámbito anglosajón: "éste es inevitablemente el futuro de la educación" 27 (profesor/a de universidad estadounidense); y "un recurso flexible y quizás un complemento necesario" ${ }^{28}$ (profesor/a de universidad de Reino Unido). Es opinión extendida que "el vídeo puede ser un material de apoyo interesante por su valor didáctico" (profesor/a de universidad española), "una herramienta absolutamente necesaria" (profesor/a de universidad españo- la), "en un contexto como el presente y entre generaciones como las de los actuales universitarios, educados en una cultura plenamente visual" (profesor/a de universidad española).

Capítulo aparte es la actitud de los estudiantes frente al vídeo y la preferencia de éstos frente a la lectura convencional de los apuntes tomados en el aula. Como reconocen la mayoría de docentes: "muchos estudiantes aprenden mejor cuando son hablados que cuando únicamente leen información, lo que convierte a este tipo de vídeos en complementos a tener en cuenta como valiosos complementos a la lectura y los apuntes" $^{29}$ (profesor/a de universidad estadounidense). En el caso particular de las disciplinas en las que el conocimiento emana no solo del texto sino también del grafismo (fotografías, planos, mapas, reconstrucciones, vídeos, etc.) el soporte audiovisual "debe ser una herramienta fundamental del discurso expositivo del docente" (profesor/a de universidad española). A esto cabe sumar la creciente propensión del discente (cada vez más familiarizado con las nuevas tecnologías) a convivir con los formatos audiovisuales, motivo por el cual muchos docentes asumen que el vídeo "es de gran utilidad y conecta especialmente con las costumbres de los jóvenes que acceden a la universidad" (profesor/a de universidad española).

Y respecto a la posibilidad de que una vídeo-lección merezca la categoría de "bibliografía recomendada" por un docente o investigador, la mayoría de encuestados reconocen que "el vídeo es un medio útil en la enseñanza universitaria" (investigador de centro científico español); y son muy pocos los que le niegan a la vídeo-lección el reconocimiento de rigor académico (figura 6).

Sí se detecta una mayor receptividad del profesorado y el estamento investigador español al vídeo, como contenido académico válido, frente a una actitud más recelosa por parte de los profesores e investigadores foráneos. Pero en esta opinión no debe obviarse el hecho de que la vídeo-lección empleada como muestreo (sobre el Círculo A de Micenas) haya sido locutada en castellano (subtitulada al inglés), motivo que justificaría la mayor participación de docentes e investigadores españoles frente a encuestados de naciones que no son castellanoparlantes. De hecho, han respondido la encuesta 104 españoles y 89 foráneos (sobre las 3.812 encuestas enviadas) a pesar de que la encuesta ha sido enviada a más foráneos que españoles (figura 5). 
Los profesores deberían incorporar, como bibliografía recomendada, vídeos producidos con rigor académico

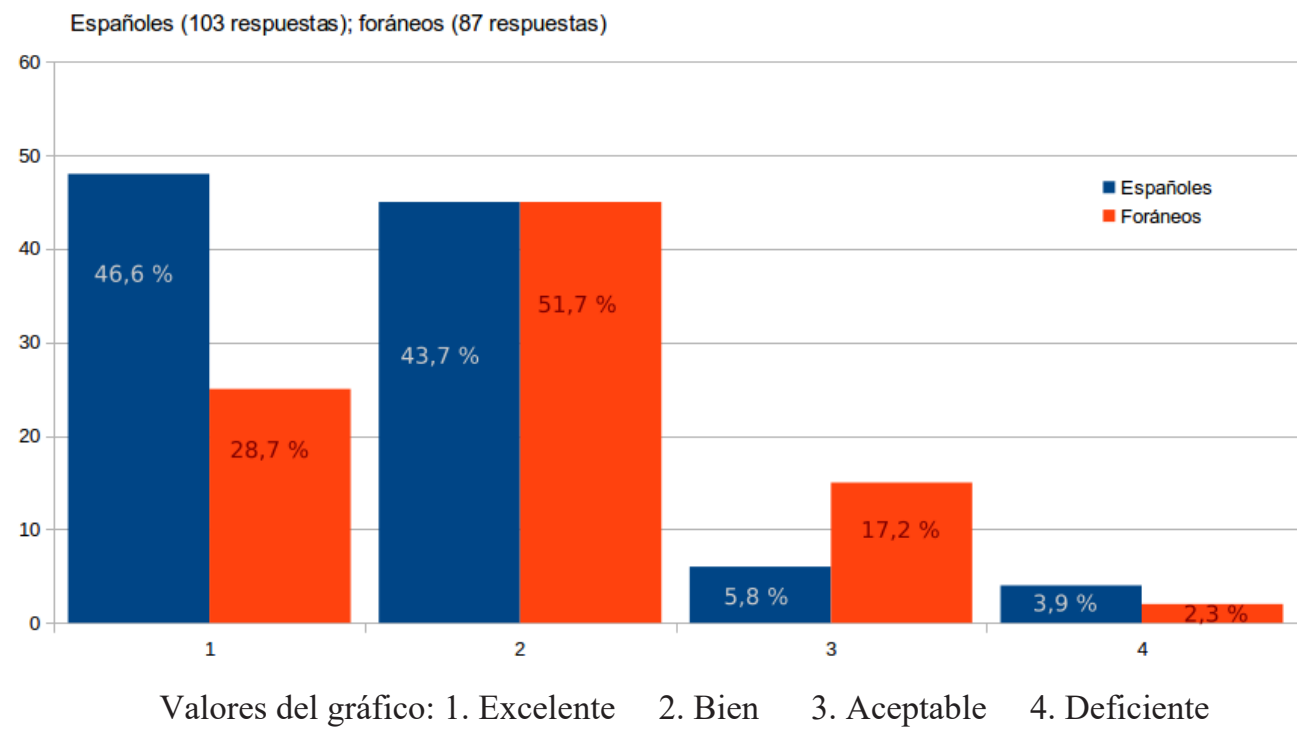

Figura 6. Gráfico resultante de haber sondeado la validez académica de los formatos audiovisuales.

Entre los docentes es mayoritaria la opinión de que "es necesario complementar las sesiones universitarias con material visual de calidad" (profesor/a de universidad española). Algunos profesores de la universidad presencial reivindican incluso una mayor implicación institucional, al considerar que "la universidad no puede ser ajena a la evolución de los tiempos y debería ser pionera en metodologías didácticas y de investigación" (docente de universidad española).

Afrontar las consecuencias de una inminente implantación del formato audiovisual, como medio de transferencia de contenidos académicos, es parte de un proceso subordinado a la propia inercia de los tiempos. De fondo late aún un tema tan delicado como la conveniencia (¿o no?) de reciclaje por parte de los docentes y el replanteamiento de las dinámicas de aprendizaje (Menéndez et alii 2015: 36). Es un error considerar el vídeo como una amenaza al rol del profesor. No deja de ser un atrevimiento, una aberración, insinuar siquiera que el profesor deba ser eliminado del engranaje educativo. Pero también es un error denostar el vídeo como complemento o suplemento académico porque "tanto la asistencia presencial a clase como la utilización de contenidos multimedia son válidos" (profesor/a de universidad española).

Los formatos audiovisuales son perfectamente compatibles con la adquisición de contenidos científicos: "proporcionan a los estudiantes material en dos o tres formatos diferentes que les permite ensayar lo que les gustaría aprender y mejorar la recepción de contenidos e ideas por repetición (...) mejor ofrecido en imágenes, diagramas, mapas, vídeos, que en discursos de conferencias o textos impresos en libros o artículos" 30 (profesor/a de universidad de Reino Unido). Sin embargo, resulta llamativa la rotundidad con la que algunos profesores de universidad niegan valor académico al vídeo. ¿Esconde esta actitud algún temor inconfesable? En ese sentido resulta especialmente reveladora la opinión de un colega anglosajón: "Opino que la principal razón por la que los profesores universitarios se oponen a los videos se debe al miedo a que sus lecciones queden obsoletas y eso implique reducción de personal. No es mi caso"31 (profesor/a de universidad de Reino Unido). Bajo este categórico comentario subyace el nada original y recurrente dilema: "tradición versus progreso". La tradición de mantener las clases presenciales como modelo único e inquebrantable; y el progreso de difundir el conocimiento a través de vídeos que pueden ser reproducidos sin condicionantes espacio-temporales.

En términos de viabilidad y rentabilidad, el vídeo está en las antípodas de la clase presencial. La decantación por los nuevos formatos audiovisuales (vídeo) acarrearía profundos cambios en la función docente $\mathrm{y}$, sobre todo, obligaría a 
una mayor racionalización de horarios lectivos para que el retorno académico fuera más productivo y rentable, haciendo más efectivos los sistemas de tutorías y favoreciendo economías de escala y costos de efectividad. Eso explica que cunda entre los profesores de universidad una cierta alarma en forma de amenaza tecnocrática: "está dando un arma a los tecnócratas que quieren reemplazar seres humanos por máquinas en educación superior"32 (profesor/a de universidad estadounidense).

No debemos confundir tecnocracia con rentabilidad. El rol del profesor es tan esencial como el tiempo requerido por un alumno (o el mismo profesor) en el proceso de adquisición de conocimientos. El vídeo brinda, ante todo, la posibilidad de economizar recursos porque "a veces no hay tiempo suficiente al haberse reducido los cursos a cuatrimestres" (profesor/a de universidad española). Polarizar el asunto con vaticinios fatalistas ("los administradores de educación superior nada desearían más que reemplazar la facultad con vídeos para reducir costes"33, comentario efectuado por profesor/a de universidad estadounidense) se antoja desacertado. No se trata de llevar el debate a un veredicto salomónico (¿el vídeo o el profesor?) sino de buscar una productiva complementariedad y simbiosis entre ambos que satisfaga a todos, en términos de rendimiento académico (Fernández Prieto 2001: 145). El vídeo no solo "descarga de preocupación y tareas al profesorado" (Pérez Navío et alii 2015: 55). Entre sus bondades cabe reseñar que propiciaría el aumento de tutorías, la atención más personalizada del estudiante y la reducción de alumnos en los grupos de clase. Incorporaría también otras alternativas viables (De Pablos 2010: 12).

Afortunadamente cada vez es mayor el número de profesores que consideran "interesante la incorporación de las nuevas tecnologías a la docencia porque supone una mejora docente y un acercamiento al alumno" (profesor/a de universidad española). Comienza a ser representativa, en el colectivo de profesores universitarios, la opinión según la cual "el vídeo es un instrumento más en el entorno universitario" (profesor/a de universidad española), además de "una iniciativa excelente y urgente" (profesor/a de universidad española). Una de las estrategias más esgrimidas por los docentes, respecto al vídeo, es aquella que se decanta por la "posibilidad de utilizarlos en clases prácticas, talleres o seminarios" (profe- sor/a de universidad española) por la versatilidad del formato en cuanto a encaje de horarios y manejo del tiempo y porque "sirve como descanso para el profesor y los alumnos sin que la actividad docente se interrumpa" (Bravo 1998: 34). Es indiscutible que "las posibilidades didácticas y potenciales de estos materiales son tan grandes y amplias en posibilidades de transmisión de conocimientos generales y de formación práctica, que merece la pena y no tiene justificación (salvo el miedo al cambio o el desconocimiento y poca familiaridad con las nuevas tecnologías) renunciar al empleo de estos materiales didácticos" (profesor/a de universidad española).

Una de las cuestiones más reveladoras, de las planteadas en la encuesta, es la que sondea la posibilidad de que la comunidad académica internacional promueva una etiqueta de garantía académica para certificar el rigor y validez de un contenido audiovisual disponible en la red (figura 7). A día de hoy no existe tal iniciativa pero es sorprendentemente abrumadora la convicción de profesores e investigadores ante la necesidad de tal etiqueta. En definitiva, un aval académico transnacional (liderado por comités de expertos) que permitiera a alumnos e investigadores depurar o purgar la gran cantidad de contenidos web que carecen de rigor y que suponen un riesgo para la comunidad universitaria. En esta consulta (figura 7) la acogida de la "etiqueta de garantía académica" es algo más tibia entre profesores foráneos, aunque sigue quedando patente la unánime receptividad a la propuesta: "es esencial encontrar un modo de dotar a los vídeos de una etiqueta de garantía ${ }^{\text {"34 }}$. (profesor/a universidad de Reino Unido).

Existe un consenso indiscutible, entre profesores de universidad y profesionales del ámbito de la arqueología y áreas de conocimiento afines, a la hora de considerar "los medios visuales y audiovisuales de todo tipo no ya una herramienta útil para la enseñanza universitaria de la ciencia histórica sino un elemento esencial e ineludible de la misma" (profesor/a de universidad española). La gran mayoría de docentes e investigadores reconoce la importancia de los grafismos (figura 8) en el proceso de aprendizaje y acepta la inclusión de las nuevas tecnologías en el proceso de transferencia de conocimientos: "los medios digitales son el futuro y pienso que marcarán la forma de producir conocimiento académico" 35 (profesor/a de universidad estadounidense). 


\section{La comunidad académica internacional debería promover una etiqueta de garantía académica para distinguir entre materiales audiovisuales aptos y no aptos desde el punto de vista académico-científico}

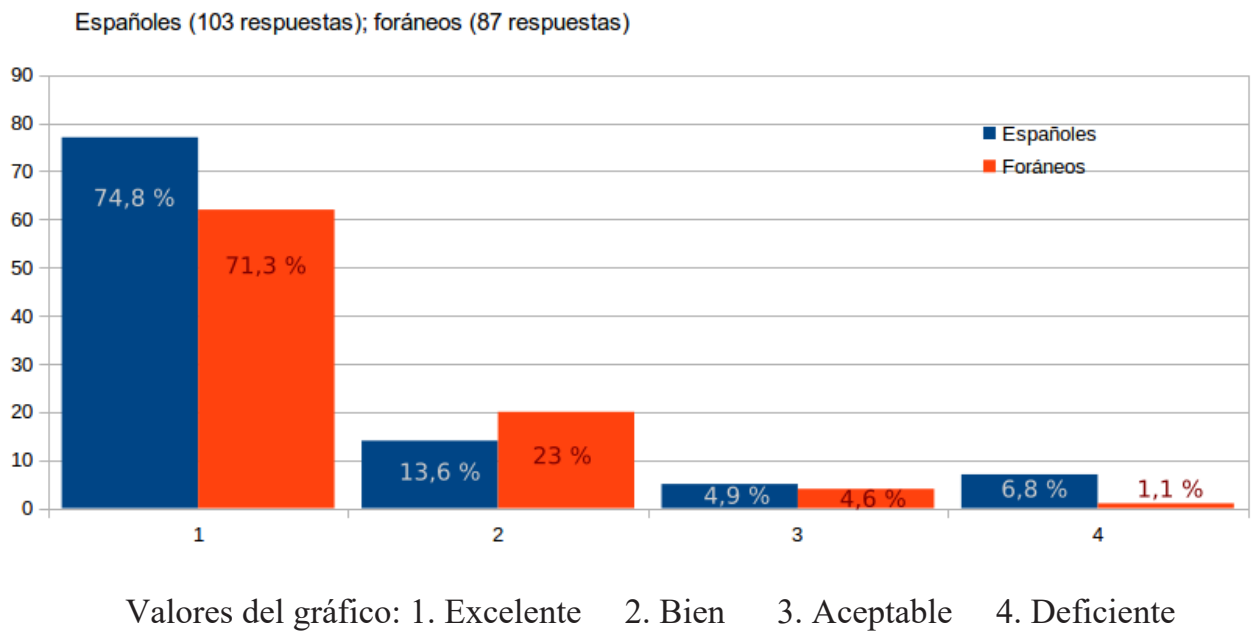

Figura 7. Gráfico resultante de haber sondeado la posibilidad de implementar una etiqueta de garantía académica.

En términos de transferencia académica, el vídeo no es la panacea. De hecho, algunos docentes e investigadores - tras visualizar el vídeo sobre el Círculo $A$ de Micenas que se adjunta a la encuesta - han emitido opiniones según las cuales "los vídeos no deben reproducir una clase tradicional sino explorar y explotar otros modelos" (profesor/a de universidad española) y "necesitamos de modelos interactivos que combinen atractivo visual y potencial explicativo" (profesor/a de universidad española). Es evidente que pueden y deben desarrollarse fórmulas que perfeccionen el vídeo - Aprendizaje Basado en Proyectos, clase invertida, gamificación, etc. - y en las que "no se abuse de las presentaciones de power points" (profesor/a de universidad noruega), que algunos docentes catalogan como "old school', (profesor/a de universidad noruega) y en las que se eviten los "bustos parlantes" 36 (profesor/a de universidad noruega), que reproducen una clase presencial: "reproduce el esquema de un experto hablando sobre una presentación de diapositivas" 37 (profesor/a de universidad estadounidense).

Críticas constructivas como las anteriores ahondan en las múltiples posibilidades del formato audiovisual ("existen también otras formas de comunicación más allá del vídeo, que también podrían ser útiles y a tener en cuenta, como por ejemplo las infografias, los podcasts y las páginas web interactivas "38, comentario de profesor/a de universidad estadounidense) y reivindican el empleo de grabaciones sobre el terreno. En esta líneas se enmarcan las siguientes reivindicaciones: "se necesita más material de filmación "39, (profesor/a de universidad belga); "grabación sobre el terreno y cámara en movimiento" 40 (profesor/a de universidad noruega), "manipulación de artefactos" "41 (profesor/a de universidad estadounidense); "debería mostrar vídeos del yacimiento" 42 (profesor/a de universidad estadounidense), si bien el perfeccionamiento de este tipo de producciones requiere de una implementación de recursos y técnicas muchas veces inaccesible para las universidades: "la creación de vídeos de calidad requiere muchos recursos" $" 43$ (profesor/a de universidad finlandesa), "tanto en conocimiento tecnológico como en destreza técnica" 44 (profesor/a de universidad estadounidense). En efecto, la escasez de medios es uno de los argumentos más aducidos: "pocas instituciones tienen todos los requisitos necesarios para crear vídeos académicos de alta calidad para cada curso; entre ellos personal con conocimientos básicos de filmación y grabación, recursos económicos y expertos dispuestos a hablar en frente de una cámara" "45 (investigador/a de centro científico austríaco). Pero más allá de la limitación de recursos técnicos y la imponderable falta de tiempo por parte del docente ("llevará mucho trabajo a los docentes ponerse al día con los contenidos multimedia, pero es necesario", comentario 
de docente de universidad española) lo cierto es que "si se contase con tiempo para preparar los trabajos y mejores medios técnicos, evidentemente los resultados serían espectaculares" (profesor/a de universidad española).

Resulta alentador, en cualquier caso, comprobar que abundan los comentarios que se decantan por incorporar el vídeo en el proceso de aprendizaje: "las vídeo-lecciones académicamente rigurosas pueden ser consideradas material educativo excelente" 46 (docente de universidad austríaca). Y es ciertamente representativo el número de docentes que plantean, como ideal, la implantación de una metodología mixta ("metodología de aula mixta"47, docente de universidad estadounidense) que alterne la modalidad presencial con el apoyo de vídeos: "la presentación del material del curso a través de vídeos de alta calidad, como éste sobre el "Círculo A de Micenas", priori- zan que en la sesión de clase el profesor pueda usar sesiones de clase para generar discusiones sobre el material expuesto, respondiendo a preguntas de los estudiantes, etc. Los estudiantes de hoy en día se encuentran más orientados visualmente en su aprendizaje"48 (docente de universidad estadounidense). Buen ejemplo de esta propuesta mixta es la que incide en las "comodidades" espacio-temporales de las vídeo-lecciones para cubrir ausencias del profesor: " usaría herramientas como ésta como suplemento, para recomendar a personas interesadas que no pueden asistir a mis propias clases, o sobre temas más allá del contenido de las clases; o tal vez para completar un tema si tuviera que ausentarme por algún compromiso académico"49 (docente de universidad estadounidense). Otra utilidad que redunda en las bondades del vídeo y su empleo como herramienta docente alternativa.

\section{La arqueología y disciplinas afines deben explicarse con soportes audiovisuales (fotografías, vídeos, imágenes de dron, reconstrucciones, mapas, planos)}

Españoles (103 respuestas); foráneos (87 respuestas)

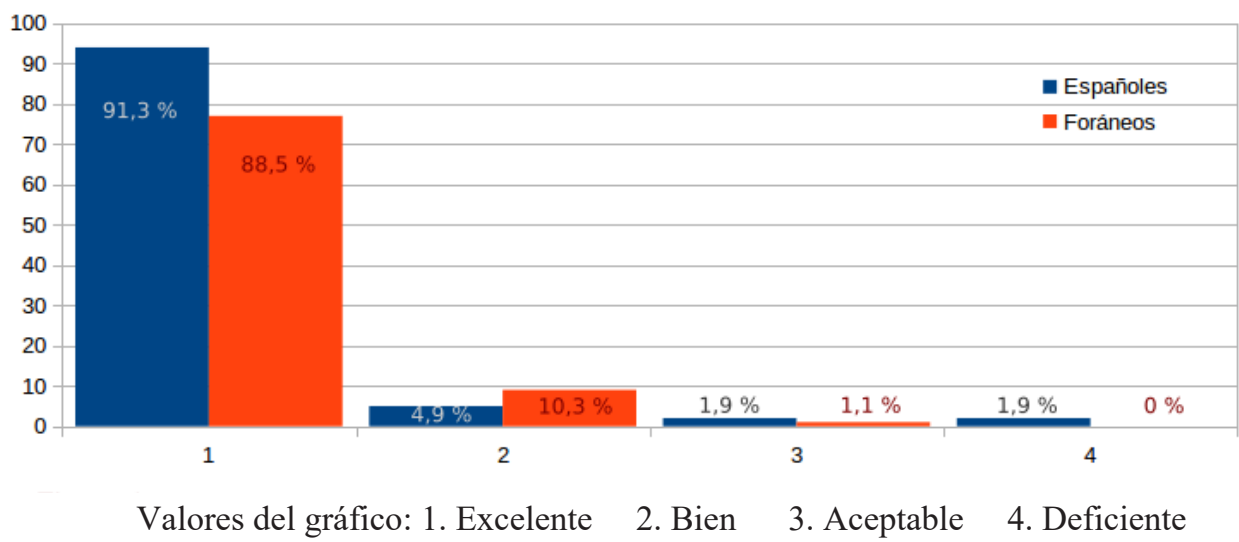

Figura 8. Gráfico resultante de haber sondeado la idoneidad de recurrir a soportes audiovisuales en la enseñanza de la arqueología y disciplinas afines.

Sería un error hacer apología del vídeo. No debe olvidarse que el vídeo no exime de la responsabilidad docente de que el contenido sea de la máxima calidad y rigor científico. El riesgo de descuidar el contenido (el fondo) frente al formato vídeo (forma) existe; "un riesgo que, por otro lado, no es exclusivo de los soportes audiovisuales: aún más empobrecedor es el que los alumnos se limiten a los apuntes" (investigador/a de centro científico español). En ningún caso, el vídeo debe suplir la lectura de literatura científica porque se trata de "estrategias docentes complementarias y no ex- cluyentes" (docente de universidad española) y "no significa que los libros se dejen de utilizar ni que se quite currículo pero si que es una forma de metodología e incluso de evaluación más avanzada que puede reportar muchas ventajas a la nueva educación" (investigador/a de centro científico español).

\section{Desafíos para el futuro}

En los últimos años venimos asistiendo al complejo proceso de transformación en la uni- 
versidad, lo que implica adaptar la estructura académica hacia una nueva horma de paradigma educativo. Una de las cuentas pendientes del estamento universitario es la colaboración inter-institucional y la creación de consorcios. A día de hoy los intereses económicos, institucionales y políticos condicionan el marchamo de las universidades en la producción de material docente y conocimiento académico. Más allá de colaboraciones espontáneas, conferencias, congresos o intervenciones puntuales de profesores e investigadores (y de que los alumnos tienen acceso a la literatura científica publicada) lo cierto es que lo producido en las aulas es de consumo exclusivo para los alumnos que acuden, de forma síncrona, al aula física. Ya fue mencionada (en el epígrafe 3) la idoneidad de la vídeo-entrevista como nutriente y recurso académico: el especialista, en una subárea concreta, rebasa el conocimiento del profesor de la asignatura. Pero se echa en falta un mayor despliegue de trabajo colaborativo entre universidades y centros científicos; y "sería interesante gestar proyectos de colaboración entre universidades para elaborar y potenciar la disponibilidad de contenidos audio-visuales contrastados y actualizados" (docente de universidad española). Compartimos el argumento según el cual "ninguna universidad es fuerte en todos los campos" (Salinas 2004: 9), lo que convierte en necesaria la alianza entre instituciones, el fomento de sinergias entre universidades y empresas (Marqués 2008: 9) y la formación de equipos interdisciplinares que reviertan en la calidad de los programas docentes. Un contexto que tienda a la "universidad expandida" (Area 2010: 66) y a la colaboración internacional entre docentes (Gómez 2016: 122-126). A día de hoy se echa en falta una mayor reciprocidad y despliegue de sinergias entre universidades y departamentos afines.

En cierto modo, la prevención frente al vídeo y a la idea de la intercambio/préstamo de contenidos docentes, por parte del sector más ortodoxo del profesorado, esconde una actitud desconfiada y recelosa. Algunos docentes ven con suspicacia el hecho de que el alumno incorpore contenidos académicos no proporcionados por el mismo profesor que imparte la asignatura, oponiéndose a la autogestión del alumno a la hora de elegir sus fuentes bibliográficas. Pero deberíamos aspirar a que en un futuro cualquier alumno tuviera acceso a un amplio corpus de vídeos en red, de contrastado rigor académico, que le permitieran acceder al conocimiento y aprehenderlo sin las limitaciones de la presencialidad. De esta manera, los vídeos serían producidos solo por especialistas en la materia, lo que revertiría en la calidad de los contenidos.

Como reto a futuro, sería interesante promover además una categoría de "call for videos", que se sumara al ya clásico "call for papers" a la hora de poner en marcha convocatorias de congresos, simposia y eventos de carácter científico o académico. Se ampliaría así el elenco de formatos y éstos perdurarían en el tiempo, generando así una vía de conocimiento alternativa, rápida, ágil y visualmente atractiva.

Actualmente la virtualización de las aulas es un esfuerzo mínima o nulamente reconocido por las agencias calificadoras. La Declaración de Bolonia de 1999 se marcó como objetivo desarrollar sistemas para la acreditación de la calidad de los sistemas de enseñanza. Pero las buenas intenciones quedaron diluidas en un limbo de interpretaciones que siempre desembocan en la misma realidad: apenas se valora la producción de vídeos de calidad (Gros y Lara 2009: 244). Resulta descorazonador que la excelencia docente siga midiéndose "al peso" (según las agencias: a mayor número de horas, mayor calidad) y nada se diga acerca de los esfuerzos innovadores en la producción de vídeos en las figuras de profesor titular y catedrático. Solo se contempla el mérito en las figuras de ayudante doctor y contratado doctor, y de una manera residual. Es una realidad que el alumno demanda y agradece el acceso a vídeos académicos. Por eso cabe preguntarse: ¿por qué las agencias calificadoras recurren al ninguneo de un recurso didáctico tan demandado por los alumnos?, ¿por qué los auditores de la ANECA miran para otro lado cuando se trata de valorar el mérito? La brecha abierta entre el primer eslabón del engranaje educativo (alumno) y el último (agencia calificadora) revela la miopía de un estamento que incurre en contradicciones. ¿Hasta cuando?

\section{Conclusiones}

La universidad necesita revisar paradigmas y acometer su propia renovación. Ante un contexto de envolvente revolución tecnológica, hipercomunicación y demanda de eficiencia, la educación superior debe adecuar sus mecanis- 
mos a un entorno de sociedad interconectada y conocimiento transfronterizo. El aula física se ha revelado como una estrategia anacrónica de escaso retorno académico con la que se incurre en la privación del conocimiento a millones de personas. No queda registro de los contenidos transferidos - el sistema de toma de apuntes no es más que un simple dictado; un procedimiento mecanicista e improductivo - y no contempla la posibilidad de reproducir o recuperar las clases impartidas. Viene siendo urgente, como desideratum, la implantación de un modelo de aula abierta, dinámica y en sintonía con la sociedad de la información y el conocimiento del siglo XXI.

En el ámbito de la transferencia académica, la herramienta que más prestaciones ofrece es la vídeo-lección, que no solo facilita la retención de contenidos sino que contribuye, en pleno auge de la cultura audiovisual, a la representación gráfica del conocimiento. El vídeo, además, garantiza su permanencia y mejora la accesibilidad: siempre estará disponible en la red. Otra modalidad generadora de conocimiento es la vídeo-entrevista, que permite al profesor titular de una asignatura interactuar con colegas mediante aportaciones académicas - novedades bibliográficas, teorías, discusiones - trasladadas por especialistas en subáreas de conocimiento en las que el titular de la asignatura no es experto. Un nuevo reto que flexibiliza los cánones de enseñanza-aprendizaje desde la transversalidad académica, la creciente conectividad, el modelo cooperativo y las redes educativas virtuales. Se antoja necesario dotar a las universidades de medios técnicos (producción, grabación, edición) que hagan viable y rentable el esfuerzo llevado a cabo por los docentes. La solución no pasa por exterminar la universidad presencial sino por maximizar el tiempo invertido por los docentes y no entrar en un bucle de repetición de las mismas lecciones año tras año.

Pero la asunción de las nuevas tecnologías (y por ende, el vídeo) por parte del profesorado universitario es hoy un debate en combustión. Una encuesta realizada en 2017 - en el área de historiadores/arqueólogos, a profesores de 180 universidades españolas, europeas y norteamericanas - muestra aún un cierto escepticismo ante el empleo del vídeo como herramienta docente. Algunas de las opiniones refractarias al vídeo apuntan a la coartada corporativista. Ven en los formatos audiovisuales una amenaza tecnocrática: no admiten la optimización de recursos que acarrearía el vídeo ni quieren reconocer la racionalización del tiempo que implicaría como recurso. Afortunadamente cada vez es mayoritaria la receptividad del estamento académico ante el empleo de formatos audiovisuales, como complemento a la presencialidad, sin menoscabo del rigor científico. Muchos (incluido el autor de este artículo) se decantan por una metodología mixta que combine la clase presencial con el uso del vídeo y algunos asumen que el formato audiovisual sería una fórmula válida para compensar las limitaciones presupuestarias de las universidades.

El proceso de aprendizaje que se estila en las universidades presenciales debe ser retocado y adaptado a los modelos en curso. Los profesores han de ser provistos de nuevas destrezas para que la transferencia académica sea más racional y versátil, con la vista puesta en un escenario futuro en el que el conocimiento sea un bien común, patrimonio de todos.

\section{Notas}

1. *El firmante de este artículo agradece la inestimable ayuda prestada por Shannon K. Jones, Carlos Segade, Nieves de Mingo (Universidad a Distancia de Madrid) y Davinia Sánchez (Universidad Complutense de Madrid) en labores de traducción; Antonio Crego (Universidad Pontificia de Salamanca) en psicología; Carolina Fernández Castrillo (Universidad Carlos III de Madrid) en el área de comunicación audiovisual; Julián Roa y Abel González (Universidad a Distancia de Madrid) en el área de nuevas tecnologías; Rodolfo Gordillo y Cira Vanessa Fernández Chamorro (Universidad a Distancia de Madrid) en estadística aplicada a encuestas; Sergio Comerón (Universidad a Distancia de Madrid) en el diseño de formularios; Mar de los Santos y Alejandra González (Universidad a Distancia de Madrid) en labores de edición y posproducción de vídeos; y Ana Landeta, directora I+D+I en la Universidad a Distancia de Madrid.

2. En julio de 2017 se celebró en la Universidad Complutense de Madrid un seminario sobre "Universidad y Sociedad. La respuesta a los grandes retos sociales".

3. Condujo a la creación del Espacio Europeo de Educación Superior (EEES), como marco educativo creado en 1999 con el fin de armonizar los sistemas educativos de la Unión Europea. 
4. Se ha llegado a emplear como metáfora la figura de "profesor orquesta" en el artículo web http:// www.elmundo.es/f5/campus/2016/12/21/585999eee2704e98698b45fc.html, publicado por Mar Villasante en diciembre de 2016.

5. Existe cierto consenso en que Bolonia, Salerno, Oxford y París son los primeros centros que merecen la consideración institucional de universidades europeas. En España fueron Palencia y Salamanca.

6. Se trata de una comunidad que fomenta las prácticas de apertura científico-divulgativa (open Access, open data, open methods) a partir de cinco premisas: proveer de herramientas y servicios de eficiencia científica, acercar la ciencia a los "no científicos", medir el impacto de las publicaciones, democratizar el acceso al conocimiento (gratuito) y promover una investigación colaborativa eficiente.

7. Buenos ejemplos de series son también Espacio Aegyptos y Aula Prehistorica (por razones de anonimato se omite el nombre institucional). La primera, centrada en temas de actualidad egiptológica; la segunda, dedicada a asuntos relacionados con la Prehistoria.

8. Sirvan como termómetro las encuestas de satisfacción docente de una universidad online (por razones de anonimato se omite el nombre), correspondientes a los últimos semestres (curso 2016-2017 y primer semestre de 2017-2018), en las que se muestra la creciente demanda de material audiovisual, especialmente vídeo-lecciones y vídeo-entrevistas, entre el alumnado tanto de grado como de máster.

9. Antes de proceder al envío de la encuesta ha sido necesario hacer acopio de las direcciones electrónicas de los profesores encuestados, labor llevada a cabo entre junio y septiembre de 2017. A continuación se procedió al envío de la encuesta, de forma individualizada, entre septiembre y noviembre de 2017. La referida encuesta ha sido diseñada con la herramienta disponible en "google formularios".

10. En la elaboración y producción del vídeo https://www.youtube.com/watch?v=IlxlFP8NjiE fue necesario visitar el Museo Nacional de Arqueología de Atenas en septiembre de 2016. Una vez obtenidas las fotografías de piezas expuestas en las salas III y IV, correspondientes a la cultura micénica, se procedió a la documentación, grabación, edición y subtitulado del vídeo (inglés), labor que fue llevada a cabo entre octubre de 2016 y mayo de 2017.

11. Universidade de Vigo, Universidade da Coruña, Universidade de Santiago de Compostela, Universidad de Oviedo, Deusto, Universidad del País Vasco, Universidad de Zaragoza, Universidad de Teruel, Universidad de La Laguna, Universidad de Las Palmas de Gran Canaria, Universidad de Burgos, Universidad de León, Universidad de Salamanca, Universidad de Valladolid, Universidad Autónoma de Barcelona, Universitat de Girona, Universidad Internacional de Cataluña, Universitat de Lleida, Universitat Oberta de Catalunya (UOC), Universitat Pompeu Fabra, Universitat Rovira i Virgili, Universidad de Cádiz, Universidad de Almería, Universidad de Córdoba, Universidad de Granada, Universidad de Huelva, Universidad de Jaén, Universidad de Málaga, Universidad de Sevilla, Universidad Pablo de Olavide, Universidad de Alcalá, Universidad Autónoma de Madrid, Universidad Complutense, Universidad Camilo José Cela, Universidad Carlos III, Universidad de Educación a Distancia (UNED), Universidad Rey Juan Carlos, Universidad San Pablo CEU, Universidad de Navarra, Universidad de Alicante, Universitat Jaume I Castelló, Universitat de Valencia, Universidad de Extremadura, Universitat de Les Illes Balears, Universidad de La Rioja y Universidad de Murcia.

12. Centro Superior de Investigaciones Científicas (CSIC), Institut Catalá d'Arqueología Clásica y Centro de Estudios del Próximo Oriente y la Antigüedad Tardía (CEPOAT).

13. Entre los países cuyas universidades han sido encuestadas se cuentan los siguientes: EE.UU (47), Reino Unido (24), Alemania (19), Francia (8), Italia (7), Canadá (6), Suiza (5), Austria (4), Grecia (4), Suecia (4), Dinamarca (3), Noruega (2), Finlandia (2), Bélgica (2), Australia (2), Sudáfrica (1).

14. The American School of Classical Studies at Athens, Archaeological Institute of America, Cornell Institute of Archaeology and Material Studies (EE.UU), German Archaeological Institute at Athens (Alemania), British School at Athens (Reino Unido), Vienna Institute for Archaeological Science, Austrian Archaeological Institute at Athens (Austria), Irish Institute of Hellenic Studies at Athens (Irlanda), Polish Academy of Sciences (Polonia), Institute for Mediterranean Archaeology, Scuola Archaeologica Italiana di Atene (Italia), Norwegian Institute at Athens (Noruega), Swedish Institute at Athens (Suecia), Belgian School at Athens (Bélgica), Danish Institute at Athens (Dinamarca), Swiss School of Archaeology in Greece (Suiza), Netherlands Institute in Athens (Holanda), Finnish Institute at Athens (Finlandia), École Française d'Athèns (Francia), Georgian Institute at Athens (Georgia), The Zinman Institut of Archaeology (Haifa, Israel), Canadian Institute in Greece (Canadá), ARGILOS Mission Archéologique gréco-canadienne (Grecia-Canadá), Australian Archaeological Institute at Athens (Australia). 
15. https://www.rand.org/content/dam/rand/pubs/monograph reports/MR1480/MR1480.appa.pdf El link corresponde a un artículo que lleva por título "Literature review of response rates" y en el que se aportan datos estadísticos sobre el éxito de respuesta en las distintas tipologías de encuestas.

16. Texto original: "without the in-person, interpersonal interaction with professor and other students, viewing the videos is simply an act of "edu-tainment".

17. Texto original: "personal engagement with students" o el "face-to-face".

18. Texto original: "day-to-day contact between faculty and students".

19. Texto original: "personal contact between lecturers and students".

20. Texto original: "direct relationship between profesor and students".

21. Texto original "a video cannot answer to any request from students".

22. Texto original: "passive way of learning".

23. Texto original: "tendency to inflate the importance of pictures".

24. Texto original: "might be attractive to inform non-academic people".

25. Texto original: "videos are useful tools in pedagogy and there is every reason to use them if they are relevant and intellectually sound".

26. Texto original: "excellent use of video-lessons is an effective way to aid students".

27. Texto original "videos certainly have a useful part to play in teaching".

28. Texto original: "this is the inevitable future of education".

29. Texto original: "an exciting and perhaps necessary additional resource".

30. Texto original: "many students learn better when being spoken to rather than just reading information, which makes these types of videos valuable additions to assigned readings and notes".

31. Texto original: "giving students material in two or three different formats allows them to rehearse what you wish them to learn, and improve the uptake of information and ideas by repetition (...) better offered in images, diagrams, maps, videos, rather than in the spoken word in lectures or the printed word in books or learned journals".

32. Texto original: "I think the main reason people oppose videos is due to fear that they could make lectures obsolete, meaning less staff required. I don 't think that myself".

33. Texto original: "you are giving a weapon to the technocrats to replace human beings with machines in higher education".

34. Texto original "administrators of higher education would like nothing more than to replace living faculty with videos simply ir order to reduce costs".

35. Texto original: "it is essential that a way is found to provide them (videos) with the quality guarantee label mentioned".

36. Texto original: "Digital media is the way of the future and I believe will redefine the way we do scholarship".

37. Texto original: "talking heads".

38. Texto original: "reproduce the scheme of an expert talking over a ppt slide presentation".

39. Texto original: "there are also other forms of media beyond video that could be helpful to consider as well, such as infographics, podcasts and interactive websites".

40. Texto original: "more film material is needed".

41. Texto original: "film on location and use moving camera".

42. Texto original: "handling artifacts".

43. Texto original: "should show videos of the site".

44. Texto original: "creating credible video lectures requires a lot of resources".

45. Texto original: "both in technology and technical skill".

46. Texto original: "few institutions have all prerequisites to create high-quality teaching videos for every course (among them staff with basic filming know-how, money and experts willing to speak in front of the camera".

47. Texto original: "academically rigorous video-lessons can be regarded as excellent educational material".

48. Texto original: "mixed classroom methodology".

49. Texto original: "presentation of course material via required viewing of a high quality videos, such as this one (Circle A Mycenae) PRIOR to class session can allow the professor to use class sessions for higher order discussion of the material, answering of student questions, etc. Contemporary students are more visually oriented in their learning...". 
50. Texto original: "would use tools like this for supplements, to recommend to interested people who can't take my own classes, or on subjects beyond the class content, or perhaps to fill in if I had to be away for a class meeting".

\section{Bibliografía}

Agís Villaverde, M. (2008): Los orígenes de la universidad en Europa y los desafíos del futuro. Agís Villaverde, M.; Baliñas Fernández, C.; Ríos Vicente, J. (coord.), Galicia y Japón: del sol naciente al sol poniente: $183-196$.

Area Moreira, M.; Hernández Rivero, V. (2010): La producción de material educativo multimedia: tres experiencias de colaboración entre expertos universitarios y colectivos docentes no universitarios. Tendencias Pedagógicas, 16: 65-88.

Carrasco Pérez, J. (2015): La Europa de las universidades. Revista del CEHGR, 27: 167-178.

Cabero, J. (2007): Las necesidades de las TIC en el ámbito educativo: oportunidades, riesgos y necesidades. Revista Tecnologías y Comunicación Educativas, año 21. 45: 5-19.

Casas, M. (2005): Nueva universidad ante la sociedad del conocimiento. Revista de Universidad y Sociedad del Conocimiento. 2(2): 1-18.

Cebrián, M. (1995): Información audiovisual. Concepto, técnica, expresión y aplicaciones. Síntesis, Madrid.

De Pablos, J. (2010): Universidad y sociedad del conocimiento. Las competencias informacionales y digitales. Revista de Universidad y Sociedad del Conocimiento (RUSC). 7(2): 6-16.

Espino Datsira, S. (2012): La toma de apuntes, su uso y enfoque de aprendizaje en estudiantes universitarios. Tesis doctoral. Universidad de Barcelona, Barcelona.

Fernández Díaz, A.; Vízcaíno Sánchez, J.; Ros Sala, M. M.; Ramallo Asensio, S. F. (2014): Arqueología y TIC. Hacia una enseñanza/aprendizaje transversal en Secundaria. Propuesta de Innovación en Arqueología de la Universidad de Murcia (España), Historia y Comunicación Social. 19: 425-438.

Fernández Prieto, M. S. (2001): Las nuevas tecnologías en la educación. Análisis de modelos de aplicación. Universidad Autónoma de Madrid, Madrid

Gómez, J. (ed.) (2016): UNIVERSITIC 2016. Análisis de las TIC en las universidades españolas. CRUE. Universidades Españolas, Madrid.

Gómez García, M. N. (1986): Las primeras universidades europeas: anotaciones sobre sus características diferenciadoras. Cuestiones Pedagógicas. 3: 11-22.

González-Peña, P.; Torres, R.; Barrio, V. del; Olmedo, M. (2017): Uso de las nuevas tecnologías por parte de los psicólogos españoles y sus necesidades. Clínica y salud. 28: 81-91.

Gros Salvat, B.; Lara Navarra, P. (2009): Estrategias de innovación en la educación superior: el caso de la Universitat Oberta de Catalunya. Revista Iberoamericana de Educación. 49: 223-245.

Gumbau Mezquita, J. P. (2006): La universidad orientada a los servicios: una perspectiva sistémica de cambio permanente por la innovación tecnológica. Revista Universidad y Sociedad del Conocimiento. 3(1): 21-43.

Herrán, A. de la (2005): Formación y transversalidad universitarias. Tendencias Pedagógicas, 10: 223-256.

Infante Moro, A.; Santos Fernández, N.; Muñiz Ronchel, C.; Pérez Medina, L. (2010): Aplicación del polimedia en el ámbito educativo. Revista DIM (Didáctica, Innovación y Multimedia), 18: 1-7.

Marqués Graells, P. (2008): Impacto de las TIC en la enseñanza universitaria. Revista DIM (Didáctica, Innovación y Multimedia), 16: 1-15.

Menéndez, L.; Guerra, D.; Montero, A. (2015): Buscando salidas: la didáctica. El arqueoturismo y las nuevas tecnologías en arqueología. La Linde, 4: 36-64.

Mora, F. (2013): Neuroeducación: solo se puede aprender aquello que se ama. Alianza Editorial, Madrid

Navarro Espejo, A. (2016): Los estilos de aprendizaje en primaria: visual, auditivo y kinestésico. Publicaciones didácticas, 75: 21-46.

Ofelia Chaile, M. (2012): Proceso de validación de materiales multimedia para la enseñanza. La recurrencia a la investigación-acción. Revista Contemporaneidad, educación y tecnología, 2(I): 72-85.

Parga-Dans, E. (2012): Estructura y desafíos de la arqueología comercial en España. Un proceso de innovación social. Revista d'Arqueologia de Ponent, 22: 87-100. 
Pérez Navío, E.; Lama Vázquez, F. M.; Maldonado Berea, G. A. (2006): Evaluación de la vídeo conferencia en el proceso de enseñanza-aprendizaje de la universidad veracruzana (México). V Congreso Internacional de Educación y Sociedad. Granada.

Pérez Navío, E.; Rodríguez Moreno, J.; García Carmona, M. (2015): El uso de mini-videos en la práctica docente universitaria. Edmetic. Revista de educación mediática y TIC, 4(2): 51-70.

Rascón Marqués, S.; Sánchez Montes, A. L. (2008): Las nuevas didácticas aplicadas a la didáctica del patrimonio. Pulso, 31: 67-92.

Rivero, P.; Feliu, M. (2017): Aplicaciones de la arqueología virtual para la educación patrimonial: análisis de tendencias e investigaciones, Estudios pedagógicos, 43(4): 319-330.

Salinas, J. M. (1995): La producción universitaria de televisión y vídeo educativos: entre la coproducción y la cooperación, Cabero-Almenara, J.; Aguaded Gómez, J. I. (coord.), Educación y medios de comunicación en el contexto iberoamericano: 103-120.

Salinas, J. (2004): Innovación docente y uso de las TIC en la enseñanza universitaria. Revista Universidad y Sociedad del Conocimiento, 1(1): 1-16.

Sebastián Pascual, L. (2016): La pastilla verde. Meridiano, Madrid.

Simone, R. (2001): La tercera fase. Formas de saber que estamos perdiendo. Taurus, Madrid.

Tedesco, J. C. (2000): Educar en la sociedad del conocimiento. Fondo de Cultura Económica, Buenos Aires-Mexico DF.

Tejado Sebastián, J. M. (2005): Escaneado en 3D y prototipado de piezas arqueológicas: las nuevas tecnologías digitales en el registro, conservación y difusión del patrimonio arqueológico, Iberia, 8: 135-158.

Tünnerrnann Bernheim Marilena de Souza Chaui, C. (2003): Desafíos de la Universidad en la Sociedad del Conocimiento, Cinco Años Después de la Conferencia Mundial sobre Educación Superior, UNESCO. Forum Occasional Paper Series Paper, 4(S): 1-31.

Veugelers, R.; Del Rey, E. (2014): The contribution of universities to innovation, (regional) growth and employment, en EENEE. Analytical Report $N^{\circ} 18$. Prepared for the European Commission.

Vicent, N.; Rivero Gracia, M. P.; Feliu Torruella, M. (2015): Arqueología y tecnologías digitales en educación patrimonial, Educatio Siglo XXI, 33(1): 83-102.

Yetter, G.; Capaccioli, K. (2010): Differences in responses to Web and paper surveys among school professionals. Behavior Research Methods, 42(1): 266-272. 